UNIVERSIDADE DE SÃO PAULO

FACULDADE DE FILOSOFIA, CIÊNCIAS E LETRAS DE RIBEIRÃO PRETO

DEPARTAMENTO DE PSICOLOGIA

PROGRAMA DE PÓS-GRADUAÇÃO EM PSICOBIOLOGIA

MARIA ELISA KUSANO

Assimetrias nos reconhecimentos de expressões faciais entre hemicampos visuais de homens e mulheres

Ribeirão Preto - SP

2015 
MARIA ELISA KUSANO

\title{
Assimetrias nos reconhecimentos de expressões faciais entre hemicampos visuais de homens e mulheres
}

\author{
Dissertação apresentada à Faculdade de Filosofia \\ Ciências e Letras de Ribeirão Preto - USP para \\ obtenção do título de Mestre em Psicobiologia.
}

Área de Concentração: Psicobiologia.

Orientador: Prof. Dr. Sérgio Sheiji Fukusima 
Autorizo a reprodução e divulgação total ou parcial deste trabalho, por qualquer meio convencional ou eletrônico, para fins de estudo e pesquisa, desde que citada a fonte.

Kusano, Maria Elisa

Assimetrias nos reconhecimentos de expressões faciais entre hemicampos visuais de homens e mulheres. Ribeirão Preto, 2015.

62 p. : il. ; $30 \mathrm{~cm}$

Dissertação de Mestrado, apresentada à Faculdade de Filosofia, Ciências e Letras de Ribeirão Preto/USP. Área de concentração: Psicobiologia.

Orientador: Fukusima, Sérgio Sheiji.

1. Expressão Facial.

2. Emoção .

3. Assimetria Cerebral. 
Kusano, M.E. Assimetrias nos reconhecimentos de expressões faciais entre hemicampos visuais de homens e mulheres. Dissertação apresentada à Faculdade de FilosofiaCiências e Letras de Ribeirão Preto - USP para obtenção do título de Mestre em Psicobiologia.

Aprovado em: 17/05/2015

\section{Banca Examinadora}

Prof. Dr.

Instituição:

Julgamento: Assinatura:

Prof. Dr.

Instituição:

Julgamento:

Assinatura:

Prof. Dr.

Instituição:

Julgamento:

Assinatura:

Prof. Dr.

Instituição:

Julgamento:

Assinatura: 


\section{AGRADECIMENTOS}

Ao meu orientador, Prof. Dr. Sérgio Sheiji Fukusima, pela paciência e ensinamentos.

Aos meus amigos, Pedro, Nayara, Chico e Joana por me ajudarem participando do experimento e Melina que participou de todas as fases desta pesquisa.

A todos os colegas de laboratório, Lina, Rui, Cris, Patrícia, Lívia e Arthur por me ajudar a concluir esse trabalho.

Ao técnico Igor, sempre disposta a ajudar e resolver os problemas que surgiam.

Aos meu pais, Tadeu e Leonilda e aos meus segundos pais, Ricardo e Elaine, que sem eles eu não teria conseguido ingressar na pós graduação.

Ao Rodrigo Acioli por sempre me apoiar nas minhas decisões.

À CAPEs, com apoio financeiro para realização do Mestrado. 


\section{RESUMO}

KUSANO, M. E. Assimetrias nos reconhecimentos de expressões faciais entre hemicampos visuais de homens e mulheres. 2014.62p. Dissertação (Mestrado). Faculdade de Filosofia, Ciências e Letras de Ribeirão Preto, Universidade de São Paulo, São Paulo, 2015 .

O reconhecimento das diferentes expressões faciais de emoções é de grande valia para as relações interpessoais. Porém, não há consenso sobre como ocorrem os processos inerentes a esse reconhecimento. Estudos sugerem diferenças no processamento de expressões faciais relacionadas à valência da emoção, assimetria funcional entre os hemisférios cerebrais, e características do observador (destreza manual, sexo e doenças) e ao tempo de exposição dos estímulos. Utilizando o método de campo visual dividido, associado ao de escolha forçada, foram investigados o desempenho de reconhecimento de faces tristes e alegres nos hemicampos visuais esquerdo e direito de 24 participantes $(13 \mathrm{M}, 11 \mathrm{H})$, todos adultos, destros e com acuidade normal ou superior. Todos foram submetidos a sessões experimentais em que pares de faces foram apresentados sucessivamente, por 100ms para um dos hemicampos visuais, direito ou esquerdo, sendo uma das faces neutra e outra emotiva (alegre ou triste), em ordem aleatória de apresentação. O gênero de cada face mantinha-se o mesmo no par (só masculina ou feminina), e trata-se da foto de uma mesma pessoa. As faces emotivas eram apresentadas aleatoriamente entre 11 níveis de intensidade emocional, obtidos pela técnica de morfinização gráfica. A tarefa do participante consistia em escolher em cada sucessão de par de faces em qual hemicampo visual encontrava-se a face mais emotiva. As taxas de acertos emcada nível de intensidade emocional de cada face emotiva permitiram estimar os parâmetros de curvas psicométricas ajustadas a curva acumulada normal para cada hemicampo visual de cada indivíduo. As análises estatísticas das taxas de acertos, em conjunto com os gráficos dos parâmetros das curvas psicométricas dos participantes, permitiu notar que houve maiores taxas de acerto às faces alegres em relação a faces tristes. Além disso, os resultados mostram que enquanto mulheres foram simétricas no reconhecimento das faces felizes e tristes, independente do hemicampo visual (HV); homens foram assimétricos: apresentaram superioridade do HV esquerdo no reconhecimento da face masculina e do HV direito em relação à face feminina. Foi possível observar diferenças no reconhecimento das faces, havendo interação entre sexo do participante e o da face-estímulo apresentada, valência da emoção e hemisfério cerebral. Este trabalho embasa parcialmente a Teoria do Hemisfério Direito e sugere que o tipo de delineamento experimental usado pode estar relacionado com a diferença de desempenho entre sexos feminino e masculino.

Palavras-chave: Expressão Facial. Emoção. Assimetria Cerebral. 


\begin{abstract}
KUSANO, M. E. Asymmetries in recognizing facial expressions between visual hemifields by men and women.2014.62p. Dissertação (Mestrado). Faculdade de Filosofia, Ciências e Letras de Ribeirão Preto, Universidade de São Paulo, São Paulo, 2014.
\end{abstract}

Recognizing different emotional facial expressions is worth for interpersonal relationship, although there is not a consensus how this recognition process really occurs. Studies suggest differences during the processing of facial expressions related with emotional valence, functional asymmetry between both brain hemisphere and observer's characteristics (manual dexterity, gender and diseases) and by the stimulus exposure time. By the divided visual field method associated with two-interval forced choice we investigated the performance of recognizing sad and happy faces in the left and the right visual hemifield of 24 participants (13 women, 11 men), all adults, right-handed and with normal or higher visual acuity. They were all submitted to experimental sessions where pair of faces were successively presented for $100 \mathrm{~ms}$ in one of the visual hemifield, right or left, being one neutral and other emotive (happy or sad), in random order presentation . Each pair of faces were only masculine or feminine, of a single person, and the emotional faces could have emotional intensity chosen randomly between 11 intensity levels obtained by computer graphic morphing technique. The participant task was to choose in each pair of face sequence in the visual hemifield which one was the most emotive. The hit rate to each level of emotional intensity of each face allowed to estimate the parameters of psychometric curves adjusted to cumulative normal distribution for each visual hemifields. The statistic analysis of the parameters of the psychometric curves allowed pointed out e that the hit rates for the happy faces were higher than for the sad ones. Also, while women showed symmetric performance in recognizing happy and sad faces between the visual hemifields, men showed asymmetric performance, with superiority of recognizing the male face in the left visual field and of recognizing the female face in the right visual field.

There were evidences that recognizing emotional faces are somewhat different, considering interaction between the gender of the participants and the gender of the stimulus face, emotional valences and brain hemisphere. This research partially supports the Right Hemisphere Theory and suggest experimental design influence the sex differences performance.

Keywords: Facial Expression. Emotion. Brain Assimetry. 


\section{SUMÁRIO}

1 INTRODUÇÃ

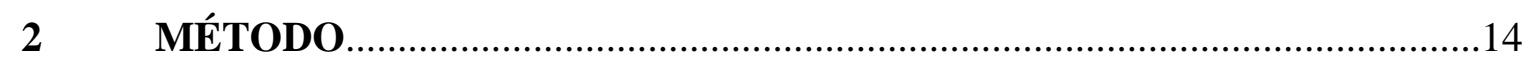

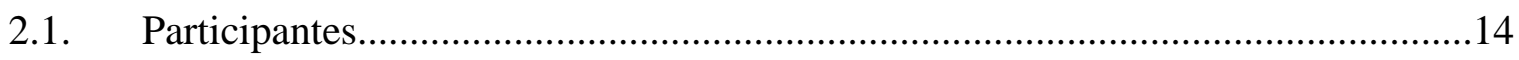

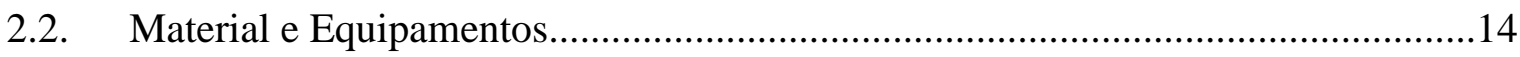

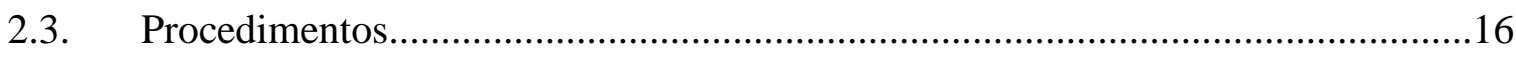

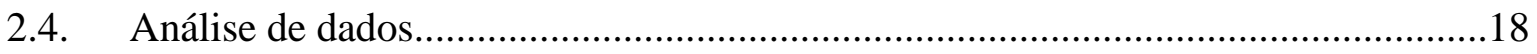

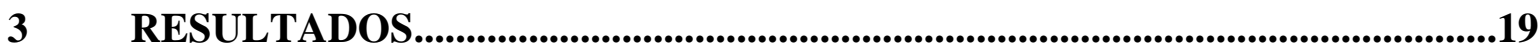

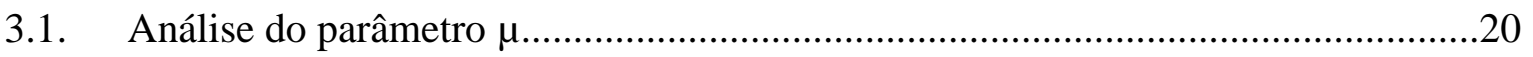

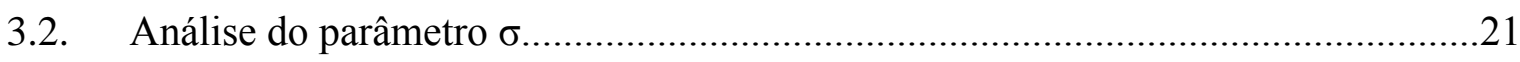

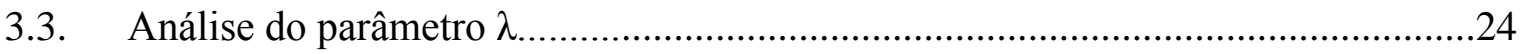

4 DISCUSSÃO

5 CONCLUSÃO

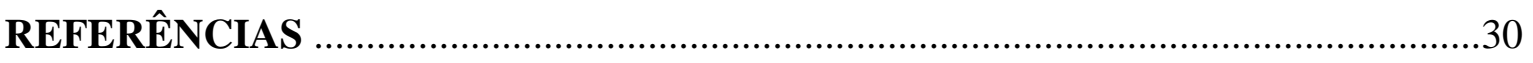

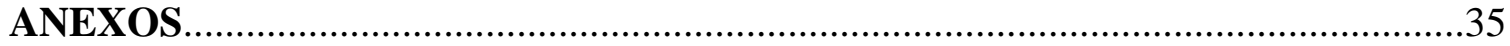

\section{INTRODUÇÃO}

Os estudos das emoções e das estruturas envolvidas no seu processamento datam de séculos atrás. Darwin,no seu livro "A expressão das emoções nos homens e nos animais", descreveu minuciosamente como o comportamento expressa emoções, como as expressões faciais se alteram devido às mudanças no estado emocional, o caráter inato das emoções e a sua importância na comunicação(Darwin, 1872/2009). 
As emoções mobilizam os indivíduos a reagirem diante de um acontecimento, estão envolvidas em tarefas fundamentais e possuem uma característica adaptativa, permitindo ao indivíduo reagir às tarefas cotidianas da melhor maneira, de acordo com suas experiências prévias. (Ekman, 1994)

Existe consenso na literatura de que as expressões faciais tem um papel relevante nas relações sociais das pessoas (Ou, 2012; Ekman, 1993; Carlson, 2004) e que o estudo das expressões faciais em indivíduos saudáveis pode auxiliar na investigação de doenças como depressão (Ekman; Matsumoto; Friesen in Ekman, Rosenberg, 1997) e ansiedade (McClure et $a l$, 2003) e estão relacionados a distúrbios como autismo, por exemplo. (Assumpção; Francisco, 1999)

O reconhecimento das mesmas expressões faciais ocorre de forma correspondente em diferentes culturas. Emoções de alegria e tristeza, por exemplo, são análogas, mesmo em tribos e grupos que supostamente nunca mantiveram contato com a civilização (Darwin, 2009). Ainda as reações emocionais de japoneses e americanos são similares segundo estudo realizado por Ekman e Keltner (1997), corroborando com a ideia de que as categorias de expressões faciais (nojo, medo, alegria, tristeza, raiva e surpresa) são de fato, universais.

A universalidade das expressões faciais pode ser atribuída a componentes das emoções per si e a fatores biológicos. Porém algumas controvérsias causadas por relações culturais podem existir (Elfenbein; Ambady, 2002).

Expressão das emoções é um assunto tão popular que Ekman (1993) afirma que pesquisas que investigam as emoções por meio de expressões faciais representam uma das áreas que crescem mais rapidamente entre as pesquisas de neurociências, e é possível encontrar uma grande quantidade de material sobre esse tema.

É possível encontrar diferentes abordagens sobre o tema. Alguns autores estudam as emoções sob uma perspectiva mais evolutiva, como Hauser (1993) que sugeriu que primatas humanos e não-humanos possuem os mesmos padrões de assimetria cerebral, pelo menos em relação ao processamento de expressões faciais. Ou ainda Robinson (1985) que propôs que o hemisfério cerebral direito de ratos está envolvido em respostas de medo.

Sob a abordagem biológica, as características estruturais das emoções são discriminadas. O giro fusiforme foi apontado como sendo a área cerebral especializada na percepção de faces (Kanwisher; McDermott; Chuun, 1997). Ishai, Schmidt e Boesiger em 
2005, revelaram que a habilidade de reconhecer faces é altamente desenvolvida em primatas, sendo necessário o recrutamento de áreas específicas do cérebro para esse processo, como a amígdala, regiões do córtex visual e córtex pré-frontal.

Haxby, Hoffman e Gobbini (2000) sugeriram que existe um sistema neural especializado na percepção facial. Segundo os autores, as faces possuem muitas características estruturais, algumas mutáveis (como o movimento dos olhos, sobrancelha e da boca) e outras fixas ou invariantes (específicas de cada pessoa) que estariam respectivamente relacionadas com a percepção da expressão facial e o reconhecimento de identidade. Porém, além de existirem estruturas relacionadas diretamente com essas características da face, Haxby, Hoffman e Gobbini (2000), ainda sugeriram a participação de outros sistemas, como o límbico, para o processamento de faces com conteúdo emocional.

É possível verificar que, ao longo dos anos, variadas pesquisas tem se configurado a fim de investigar as diferentes dimensões das expressões faciais, como assimetria cerebral, distribuição cortical e possíveis similaridades entre os seres humanos e não humanos. Para tais pesquisas, diferentes métodos de investigação são utilizados, como o campo visual dividido (Bourne, 2006; Bourne; Todd, 2004; Sato; Aoki, 2006; Alves, 2004), ressonância magnética funcional (fMRI - functional magnetic resonance imaging) (Fusar-Poli et al, 2009; Ishai; Schmidt; Boesiger, 2005; Phillips et al, 1998; Haxby; Hoffman; Gobbini 2000), escolha forçada (Frank, Stennett, 2001), análise da taxa 2D:4D (Bourne, Gray, 2008), teste de faces quiméricas (Bourne, 2011).

Dentre todas as perspectivas que estudam o reconhecimento de expressões faciais, há um amplo campo de pesquisa sobre o processamento assimétrico no reconhecimento de faces. Quando trata-se especificamente deste processamento em humanos muitas peculiaridades aparecem, como disparidades entre destros e canhotos (Bourne,2006; Everhart; Harrison; Crews, 1996), homens e mulheres (Proverbio et al, 2006; Bourne 2005; Grimshaw, BulmanFleming, Ngo, 2004; Killgore, Yurgelun - Todd, 2004), valência da emoção (Abbott et al, 2014; Lee et al, 2002), localização do estímulo no campo visual (Liu, Ioannides, 2010) e orientação da atenção (Eastwood, Smilek, Merikle, 2001; Pessoa et al, 2002).

Estudos recentes demonstraram que a localização da face no campo visual do observador pode interferir no reconhecimento da expressão facial. Liu e Ioannides (2010) desenvolveram uma pesquisa na qual as imagens tinham a possibilidade de aparecer em 5 posições diferentes (4 quadrantes e centro), e observaram que o processo assimétrico de 
reconhecimento de expressões de emoção era dependente não só do campo visual em que a imagem aparecia, mas também da valência emocional contida na face apresentada. Enquanto faces de medo foram melhor reconhecidas quando apresentadas no centro e no canto superior direito, faces felizes não apresentaram distinções relativas ao posicionamento no campo visual. Foi ainda observada a ativação cerebral precoce do hemisfério contralateral em relação ao campo visual em que a imagem era mostrada.

Assim como no estudo acima, disparidades entre emoções positivas e negativas também está documentado na literatura. Eastwood, Smilek e Merikle (2001) realizaram um estudo sobre direcionamento de atenção em faces com emoções positivas e negativas. Em sua pesquisa, faces esquemáticas com emoções positivas e negativas eram apresentadas, uma por vez, em um contexto de faces neutras. O participante deveria encontrar, o mais rápido possível, a única face com emoção. Pela análise do tempo de reação, esses autores sugeriram que faces com emoções negativas são mais efetivas ao orientar a atenção do observador.

Sato e Aoki (2006) investigaram a dominância do hemisfério direito no processamento inconsciente de emoções negativas. O delineamento experimental adotado se configurou na apresentação subliminar de uma face com valência emocional (raiva ou felicidade), seguido de um estímulo de mascaramento e, por último, de um ideograma. Os participantes responderam se gostavam ou não do ideograma apresentado no final de cada tentativa. Foi observado que, quando os estímulos de faces com conteúdo emocional negativo eram apresentados no campo visual esquerdo, os participantes demonstravam gostar menos do ideograma apresentado, sugerindo que a face com emoção negativa havia sido processada mesmo sem ter sido conscientemente percebida.

Phillips et al (1998) ao investigar o substrato neural envolvido na percepção de faces tristes e felizes sugeriram que vias anatômicas distintas são ativadas durante a percepção dessas duas expressões faciais. Enquanto que a porção anterior e posterior do giro do cíngulo e córtex frontal medial foram ativadas durante a apresentação de faces felizes, surpreendentemente, nenhuma área cerebral foi alterada na presença das faces tristes.

Similarmente com o estudo anterior, Killgore e Yurgelun - Todd (2004) também encontraram diferentes substratos neurais na percepção de faces felizes e tristes. Nesta pesquisa foram utilizados fotos mascaradas de faces, a fim de que os estímulos fossem percebidos apenas inconscientemente. O giro do cíngulo anterior, analogamente ao resultado 
de Phillips et al (1998), e ainda a amígdala foram ativados durante a apresentação faces felizes. Apenas o cingulado esquerdo foi recrutado durante a apresentação das faces tristes.

Lee et al (2002) pesquisaram as diferenças entre homens e mulheres no reconhecimento de faces tristes e felizes. Foi encontrado que, dependendo do sexo do observador, áreas cerebrais distintas são ativadas durante a observação dos estímulos. Homens e mulheres apresentaram ativação bilateral do córtex frontal e córtex parietal esquerdo quando faces felizes eram mostradas, porém somente mulheres apresentaram ativação da porção esquerda do tálamo e córtex temporal e occipital direito. A discrepância entre áreas ativadas foi muito maior no reconhecimento de faces tristes, não havendo nenhuma ativação semelhante entre homens e mulheres.

Consoante com os achados de Lee et al (2002), Bourne (2005) afirma que existem diferenças entre os sexos na tarefa de reconhecer faces. É frequente encontrar dados que asseguram que os homens são mais assimétricos do que as mulheres. Os resultados de seu estudo porém, demonstraram que, tanto homens quanto mulheres possuíam dominância lateral direita, mas os homens eram mais fortemente assimétricos. Este estudo apresentou dados pouco comuns, uma vez que geralmente é verificado que as mulheres são bilaterais.

Proverbio et al. (2006) também investigaram a relação entre sexo e assimetria hemisférica no processamento de faces. Neste estudo foram utilizadas faces neutras e com conteúdo emocional negativo (angústia). Nos resultados não foram encontradas diferenças entre gêneros para dados comportamentais (acurácia), porém foi observada assimetria em relação à latência de resposta. $\mathrm{O}$ hemisfério direito dos homens foi mais rapidamente ativado em comparação com o esquerdo. A amplitude da resposta foi maior em ambos os hemisférios das mulheres, enquanto que a amplitude foi maior no hemisfério direito masculino. Sugere-se que os dados dos homens podem estar mais relacionados com a análise que eles fazem de propriedades estruturais da face e expressões, do que com seu conteúdo afetivo, caracterizando funcionalmente a lateralização hemisférica nos homens.

Examinando a diferença entre sexos e destreza manual, Bourne (2008) encontrou diferenças entre o grau de destreza manual de destros. A autora aplicou o teste de faces quiméricas e um questionário de destreza a 313 participantes (156H e 157M). Foi encontrado que os participantes classificados como mais destros mostraram-se mais fortemente lateralizados, e ainda foi verificada diferenças entre homens e mulheres, com maior lateralização hemisférica nos homens. 
Em um estudo feito por Everhart, Harrison e Crews (1996) com indivíduos com dominância esquerda e direita (canhotos e destros, respectivamente), foram verificadas diferenças na lateralização conforme a natureza do estímulo apresentado: indivíduos com dominância lateral esquerda identificaram faces neutras como mais zangadas quando estas eram mostradas no campo visual direito em relação ao campo visual esquerdo, enquanto os destros foram mais coerentes entre os campos visuais. Além das diferenças entre sexo e destreza manual, a ideia de que possa ocorrer lateralização hemisférica nos processamentos de faces é amplamente aceita, com grande parte da literatura sugerindo superioridade do hemisfério direito sobre o esquerdo. Apesar das evidências a favor dessa superioridade, existem teorias contrastantes a respeito do processamento assimétrico das faces (Bourne, 2011).

Atualmente, existem dois modelos teóricos dominantes que explicam o processamento de emoções e expressões faciais: a hipótese do hemisfério direito e a hipótese das valências (Alves; Fukusima; Aznar-Casanova, 2008). Segundo Borod et al (1998) existe dominância do hemisfério direito no processamento de estímulos emocionais, sendo essa afirmação a base ideológica para a hipótese do hemisfério direito. A formulação de outra hipótese mais recente, a hipótese das valências, confere a ambos os hemisférios funções no processamento de emoções, determinando que o hemisfério esquerdo é dominante no processamento de emoções positivas enquanto o hemisfério direito é superior no processamento de emoções negativas (Wager et al, 2003).

Um terceiro modelo, considerado uma vertente da hipótese das valências, também propõe diferentes papéis para ambos os hemisférios cerebrais. A hipótese de aproximaçãoevitação baseia-se na influência do sistema emocional no comportamento do indivíduo. Portanto, algumas emoções eliciam um comportamento de aproximação (como alegria, por exemplo) e são processadas no hemisfério esquerdo do cérebro, enquanto outras emoções (como o medo) promovem afastamento ou evitação e estão relacionadas ao hemisfério direito. Esta teoria difere da hipótese das valências em relação à raiva. Na hipótese das valências, a raiva é classificada como uma emoção negativa e processada primariamente pelo hemisfério direito, enquanto no modelo de aproximação-evitação é considerada como a emoção que promove aproximação e portanto processada pelo hemisfério esquerdo. (Demaree et al, 2005)

Entretanto, não há na literatura, concordâncias sobre como ocorre o processamento de informações visuais contendo faces que expressem conteúdo emocional, e são encontradas 
lacunas e divergências de informações a respeito deste tema. A partir dos estudos apresentados, é possível refletir sobre como ainda encontram-se indagações a respeito do reconhecimento de faces contendo expressões emocionais, principalmente no que diz respeito a certas características individuais, como sexo do indivíduo e destreza manual.

A importância do estudo sobre expressões faciais, o que justifica a realização da presente pesquisa, fundamenta-se na compreensão do processamento cerebral em indivíduos saudáveis ou não, por exemplo, prosopagnosia, ou a incapacidade de indivíduos de reconhecer faces, por exemplo, é um distúrbio associado ao processamento de faces.

Como já foi citado anteriormente, a habilidade de reconhecer faces possui importância na comunicação, interação social e sobrevivência do indivíduo. Apresentada sua relevância, esta pesquisa teve como objetivo investigar se existem diferenças no desempenho de reconhecer faces tristes e alegres nos hemicampos visuais direito e esquerdo, de homens e mulheres. Enfatizaram-se os desempenhos individuais de cada hemisfério cerebral, comparando-os primordialmente dentro do mesmo hemicampo, ou seja, buscou-se compreender e investigar a potencialidade intra-hemisférica no reconhecimento das faces emocionais. Ainda, emoções foram analisadas separadamente, utilizando faces neutras para comparação das faces.

Investigou-se também as possíveis assimetrias hemisféricas por meio da comparação dos desempenhos dos participantes para cada hemisfério cerebral, comparando ainda as diferenças entre desempenhos de homens e mulheres.

\section{MÉTODO}

\subsection{Participantes}

\subsection{Participantes}

Inicialmente, foram coletados dados de 30 participantes, porém nem todos os dados puderam ser analisados, uma vez que 6 pessoas não conseguiram discriminar as emoções das faces apresentadas. Portanto, participaram desta pesquisa 24 participantes $(13 \mathrm{M}, 11 \mathrm{H})$ com 
idade variando de 18 a 32 anos, todos destros e com acuidade normal ou superior em ambos os olhos com ou sem lentes corretivas. Todos os participantes leram e assinaram o Termo de Consentimento Livre e Esclarecido (anexo 1) e responderam ao Inventário de Edinburgh para garantir a destreza manual (Anexo 2). A média das escores no Inventário para as mulheres foi de $69,59 \pm 17,56$ e dos homens doi de 68,07 $\pm 26,46$.

\subsection{Material e Equipamento}

Foi necessária uma sala com iluminação controlada, com mobiliários que auxiliaram na coleta de dados, como uma mesa para acomodar o computador e cadeira regulável para que o participante pudesse se sentar da maneira mais confortável possível. Foi utilizado um suporte para o queixo e testa para fixar a posição do observador; um aparelho Ortho-Rather da Bausch \& Lomb Optical Co. para medir acuidade visual; um computador acoplado a um monitor LCD de 23 polegadas e a um teclado numérico para apresentar os estímulos e coleta de respostas. O Inventário de Edinburgh (Oldfield, 1971) (Anexo 2), foi utilizado para avaliar a dominância lateral da destreza manual dos participantes.

Os estímulos para esta pesquisa foram imagens da série Pictures of Facial Affect (Ekman; Friesen, 1976). A saber, aqueles com os seguintes códigos: JJ4-8, JJ5-5, JJ3-4, A1-6, A2-6, A1-2. Essas imagens digitais são em preto e branco, de faces frontais de um homem e uma mulher, com expressões de tristeza, de alegria e com expressão neutra. As imagens das faces foram modificadas pelo programa Morph Man v.4, que gerou faces cujas expressões emocionais intermediárias foram graduadas da expressão neutra para o triste e da expressão neutra para o alegre. As graduações de morphing se deram em passos de transição de $20 \%$, obtendo-se 6 faces, da face com expressão neutra ao com expressão alegre ou ao com expressão triste; conforme mostrado na figura 1(ver todas as fotos no anexo5).

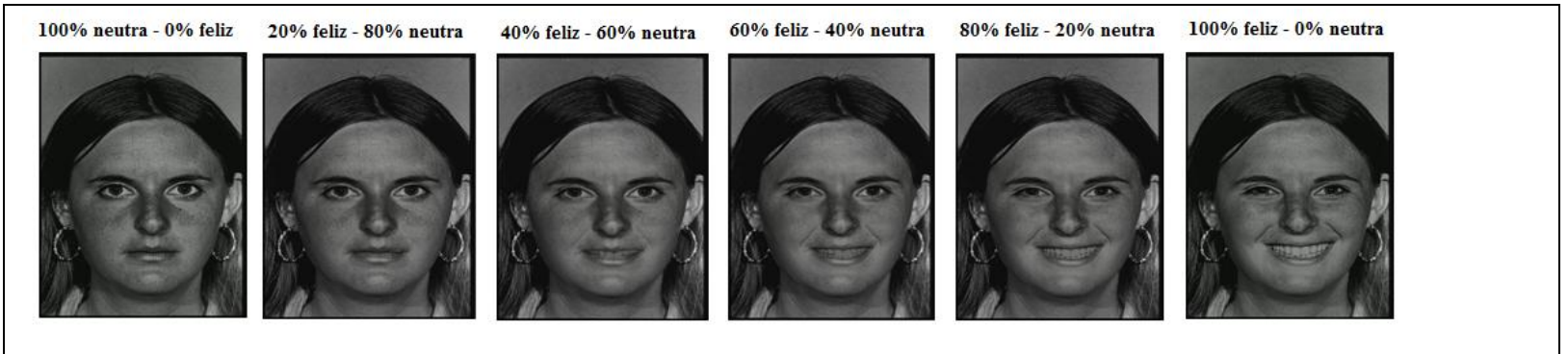

Figura 1. Exemplos de faces geradas por morphing com passos de transição de $20 \%$ de uma face com expressão neutra para outra com expressão emocional máxima (100\%) de tristeza ou alegria. 
As dimensões das imagens foram ajustadas na tela do computador para $6 \times 9 \mathrm{~cm}$ e apresentadas a $57 \mathrm{~cm}$ dos olhos do observador; que corresponderá as dimensões de $6,03^{\circ} \mathrm{x}$ $9,05^{\circ}$ de ângulo visual.

A excentricidade da borda da imagem mais próxima ao ponto de fixação foi de $2,5 \mathrm{~cm}$ ( $2,51^{\circ}$ de ângulo visual ) (Bourne, 2006), conforme mostrado na figura 2.

Figura 2

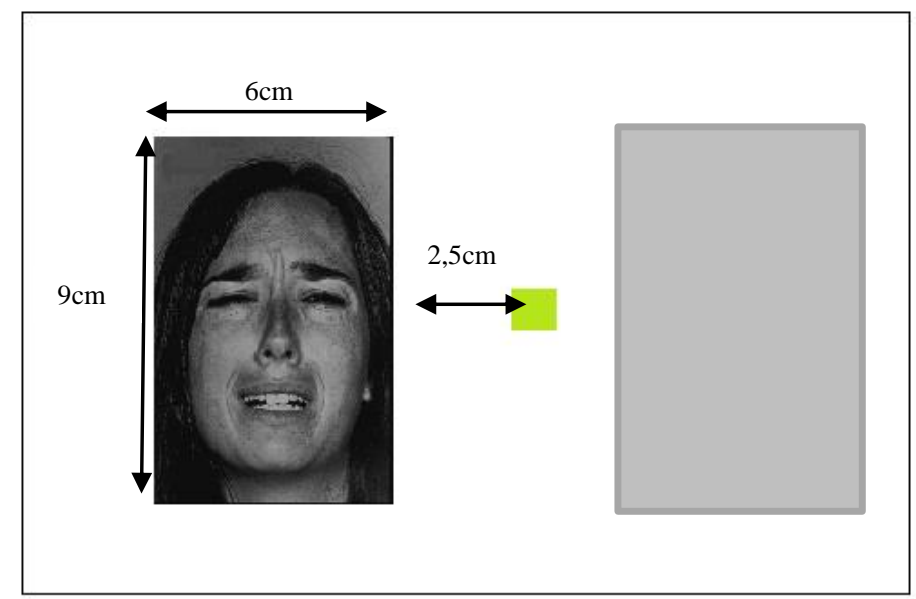

Figura 2. Dimensões da imagem e dimensões das imagens (fotografia e retângulo cinza) em relação ao ponto de fixação.

O software E-prime foi usado para apresentação dos estímulos e coleta de respostas.

\subsection{Procedimento}

Antes de dar início à sessão experimental, o participante lia e assinava o Termo de Consentimento Livre e Esclarecido . Após o consentimento, era aplicado o teste de acuidade visual utilizando o aparelho Ortho-Rather da Bausch \& Lomb Optical Co. e logo em seguida aplicado o Inventário de Edinburgh (Oldfield, 1971). 
Antes da realização da tarefa experimental explicou-se ao participante que o apoio para cabeça e queixo era para o melhor posicionamento à frente da tela do computador, onde as imagens foram apresentadas. Também se posicionou o teclado do computador a frente do observador de modo que o teclado numérico, à direita do observador, permitisse uma disponibilização confortável das teclas 1 e 2 para coleta de resposta com o dedo indicador da mão direita. Após esses procedimentos iniciou-se a sessão experimental. O participante foi instruído sobre a tarefa, cuja descrição se encontra no anexo 3.

Havia dois blocos de apresentações, A e B. No bloco A as faces sempre eram apresentadas no hemicampo visual direito e um retângulo cinza no hemicampo visual esquerdo; no bloco $\mathrm{B}$ as faces eram apresentadas sempre no campo visual esquerdo, o retângulo cinza, no hemicampo visual direito (Ver Figura 3) Para cada bloco de apresentações, a cada coleta de dados, precediam-se duas apresentações sucessivas de estímulos do mesmo bloco. Iniciavam-se com a apresentação um ponto de fixação no centro da tela, que logo após o pressionar da barra do teclado, uma face de uma pessoa e um quadrado cinza de mesma dimensão da face apareciam simultaneamente na tela por 100ms. Logo sem seguida, ambas as imagens eram mascaradas por ruído (backward masking) durante 50ms. Após isso, mostrava-se novamente o ponto de fixação e logo em seguida, de maneira similar, uma nova face e um retângulo nas mesmas localizações da apresentação anterior. Nesses pares de apresentações sucessivas sempre havia numa delas uma face neutra e na outra, a face da mesma pessoa mostrada na apresentação anterior com alguma intensidade de expressão emocional.

As alocações da face neutra e emocionais nas duas apresentações sucessivas eram aleatórias, e o sujeito deveria julgar em qual das apresentações, na primeira ou na segunda, a face emocional foi apresentada (método da escolha forçada com duas alternativas - 2AFC). Se fosse a primeira apresentação, pedia-se que pressionasse a tecla numérica 1, se fosse a segunda, a tecla 2. Em alguns pares de faces, a mesma face neutra ou a mesma face emocional de maior intensidade eram apresentadas nas duas apresentações sucessivas como catch-trials para checar posteriormente se havia tendência do participante em escolher a primeira ou a segunda apresentação como resposta.

Cada par de faces (uma neutra e outra com alguma intensidade emocional apresentadas em sucessão) em cada bloco foi apresentada 20 vezes em ordem aleatória. Em metade delas, a face emocional estava na primeira apresentação e noutra metade, na segunda 
apresentação. E as pertenças das apresentações, se do bloco A ou B, também foram intercaladas aleatoriamente.

Houve duas sessões experimentais para cada participante, uma para as faces tristes e outra para as faces alegres. As faces tristes e alegres eram de um homem e de uma mulher. Metade dos participantes, em ordem aleatória, iniciou a primeira sessão com as faces alegres e outra metade com as faces tristes.

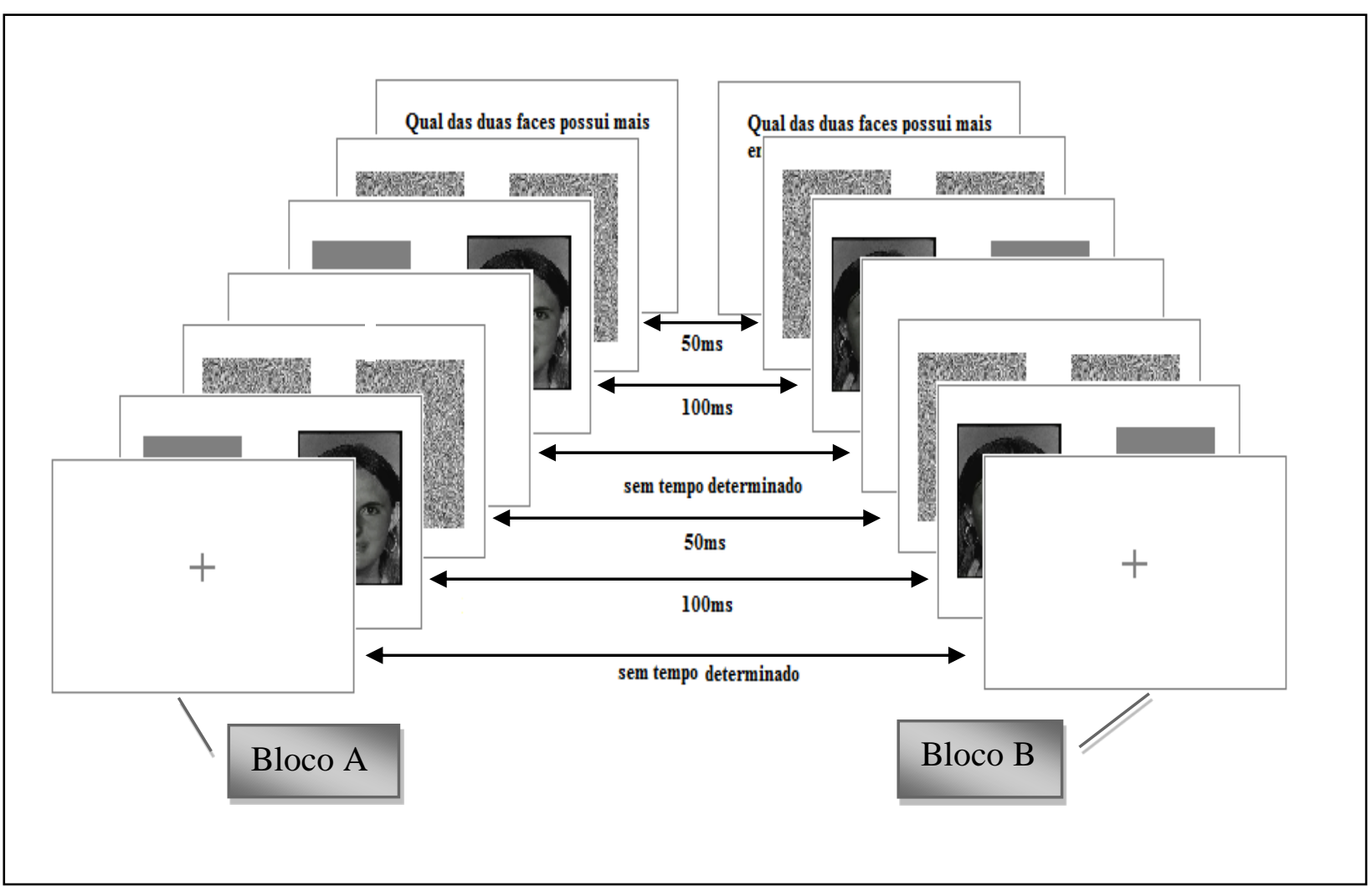

Figura 3. Esquema de apresentações dos pares de faces no hemicampo visual direito (bloco A) e esquerdo (bloco B) utilizados para sessão experimental das faces tristes e alegres. Em ambos os blocos, em ordem aleatória, em 50\% das apresentações a face neutra será exposta primeiramente e nos 50\% restantes, a face com emoção será exposta primeiramente.

\subsection{Análise de Dados}

Foram computadas as taxas de acerto de cada observador para as apresentações de pares de faces no hemicampo visual direito e esquerdo separadamente para cada nível de morphing de expressão emocional. Essas taxas de acertos foram tabeladas e utilizadas para 
traçar as curvas psicométricas (taxa de acerto x nível de morphing das faces emocionais) em que a taxa de $75 \%$ de acerto foi definida como critério para estimar o limiar de discriminação entre a face neutra e a face com conteúdo emocional em cada hemicampo visual.

Utilizando as médias feitas com os parâmetros $\mu, \sigma$ e $\lambda$ foi gerada a curva psicométrica (ver Figura4) por meio da utilização do programa Matlab (script no anexo 6). O parâmetros $\mu$ e $\sigma$ definem a curva normal, caracterizando a distribuição dos dados. Portanto, $\mu$ refere-se à média da distribuição, neste caso representando o mínimo grau de morphing necessário para o reconhecimento da face, enquanto o $\sigma$ (desvio padrão) representa um indicador da inclinação na função psicométrica. Este parâmetro pode ser tomado como um índice de sensibilidade do sujeito para reconhecer a face emocional em estudo. $\mathrm{O} \lambda$ representa o lapso, a diferença entre o máximo de acertos possível (100\%) e os acertos reais que ocorreram no teste psicométrico, e a diferença $(1-\lambda)$ determina o limite máximo de acertos da curva psicométrica. $O \lambda$ pode significar taxa de erros do participante devido à percepção errônea, falta de atenção, digitação incorreta entre outros. (Klein, 2001; Wallraven; Cunningham, 2011)( figura 4). 


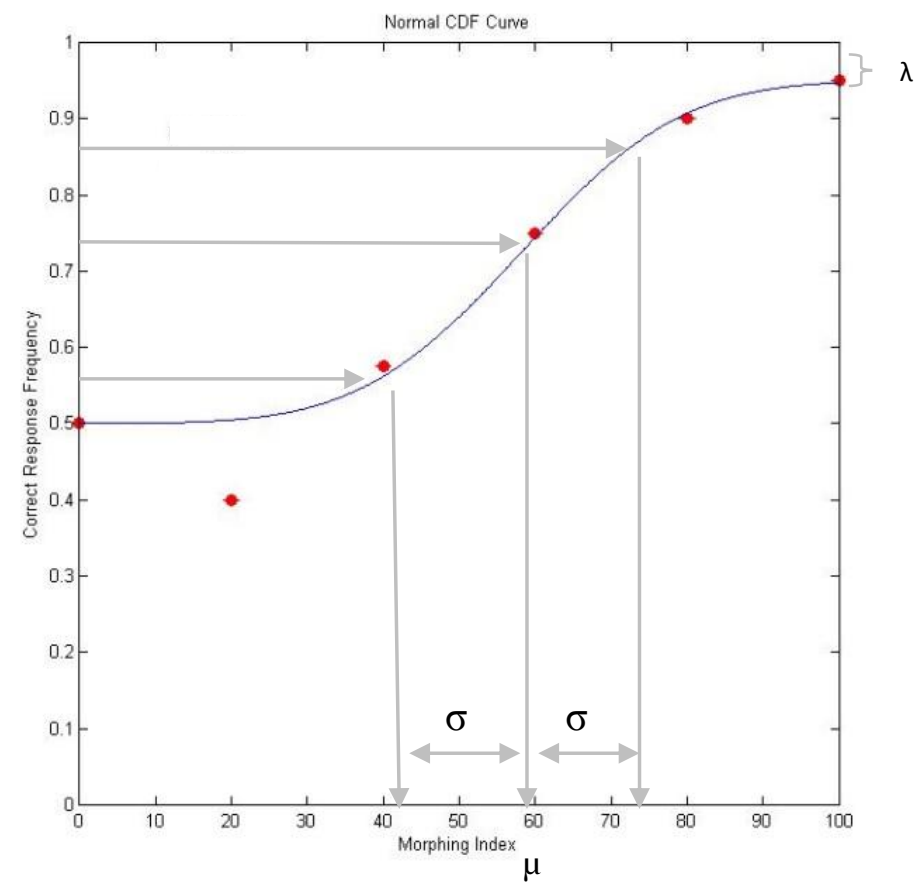

Figura 4. Curva psicométrica ajustada à curva acumulada de uma distribuição normal, cujos parâmetros são $\sigma, \mu$ e $\lambda$. Tais parâmetros são respectivamente demonstrados como a inclinação, o ponto central e o ponto máximo da curva psicométrica.

\section{RESULTADOS}

A análise estatística dos dados foi realizada com auxílio do programa SYSTAT. O teste de normalidade de Shapiro-Wilk indicou que as médias dos parâmetros $\sigma, \mu$ e $\lambda$ apresentavam distribuição normal ( $p>0,05)$. As médias dos parâmetros $\sigma, \mu$ e $\lambda$ de cada participante foram submetidas a ANOVA Between-Within four way para medidas repetidas de modelo: 2 sexos de participantes (homens e mulheres) x [2 emoções (alegria e tristeza) x 2 sexos faces (fotografias masculina e feminina) x 2 hemicampos visuais (faces alvo à direita e esquerda)]. A variável "sexo do participante" foi tomada como inter-sujeitos (betweensubjects) e as variáveis "sexo da face", "emoção" e "hemicampo visual" como fatores intrasujeitos (within-subjects).

A análise de cada parâmetro foi feita em sequência, primeiramente com cada emoção (alegria e tristeza) e combinadas ao final. As taxas de respostas de homens e mulheres foram analisadas juntas e separadas para cada caso (emoção alegre, emoção triste e as duas juntas). 


\subsection{Análise do parâmetro $\mu$}

Os resultados mostram diferenças no reconhecimento de faces felizes e tristes $[\mathrm{F}(1,22)$ $=99,355 ; \mathrm{p}<0,001]$, sugerindo que as faces feminina e masculina, triste e feliz foram reconhecidas diferentemente pelos participantes $[\mathrm{F}(1,22)=10,634 ; \mathrm{p}=0,004]$, apresentando ainda interação estatisticamente representativa entre os fatores "sexo da face", "hemicampo visual" e "sexo do participante" $[F(1,22)=10,020 ; p=0,044]$.

Homens reconheceram as faces felizes e tristes de maneira divergente $[\mathrm{F}(1,10)=$ 54,074; $\left.\mathrm{p}<\_0,001\right]$ demonstrando efeito estatístico significativo entre os fatores "hemicampo visual" e "emoção" $[F(1,10)=7,437 ; p=0,021]$ e "emoção" e "sexo da face" $[F(1,10)=6,869$; $\mathrm{p}=0,026]$. Mulheres, assim como homens, reconheceram as duas emoções de forma distintas $[\mathrm{F}(1,12)=53,107 ; \mathrm{p}=0,000]$, com interações estatísticas significativas entre as variáveis "hemicampo visual" e "sexo da face" $[\mathrm{F}(1,12)=14,453 ; \mathrm{p}=0,003]$.

Por meio da análise das faces alegres, foi observado que as fotografias feminina e masculina não foram reconhecidas de maneira análoga $[\mathrm{F}(1,22)=7,285 ; \mathrm{p}=0,013]$, havendo efeito estatístico importante entre o "hemicampo visual" e "sexo da face" $[\mathrm{F}(1,22)=5,869$; $\mathrm{p}=0,024]$. Ainda, houve interação entre o "sexo do participante" e "hemicampo visual" $[F(1,22)=5,182 ; p=0,033]$, sugerindo que homens e mulheres diferem no reconhecimento de faces alegres nos hemicampos visuais esquerdo e direito. Com a análise separada das médias, foi possível verificar ainda que apenas os homens demonstraram interação para o fator "hemicampo visual" $[\mathrm{F}(1,10)=7,222 ; \mathrm{p}=0,023]$. Assim, à medida que mulheres foram mais simétricas, homens demonstraram ser mais assimétricos no reconhecimento de faces alegres, com discreta superioridade do hemicampo visual esquerdo (fig.5)

$\mathrm{O}$ "sexo da face" interferiu no reconhecimento de faces tristes $[\mathrm{F}(1,22)=5,840$; $\mathrm{p}=0,024]$ pelos participantes. Porém o desmembramento dos dados não mostrou nenhuma interação estatística significativa entre as variáveis, tanto em homens quanto em mulheres. Porém, a observação da figura 6 indica que homens necessitaram menor grau de morphing para reconhecer as faces tristes em comparação às mulheres, inclusive a face feminina. Portanto, observando os dados apresentados na Figura 5, é possível verificar que era necessário maior grau de morphing para o reconhecimento da face feminina triste.

Todos os dados da análise estatísticas estão apresentados em tabelas no anexo 8. 

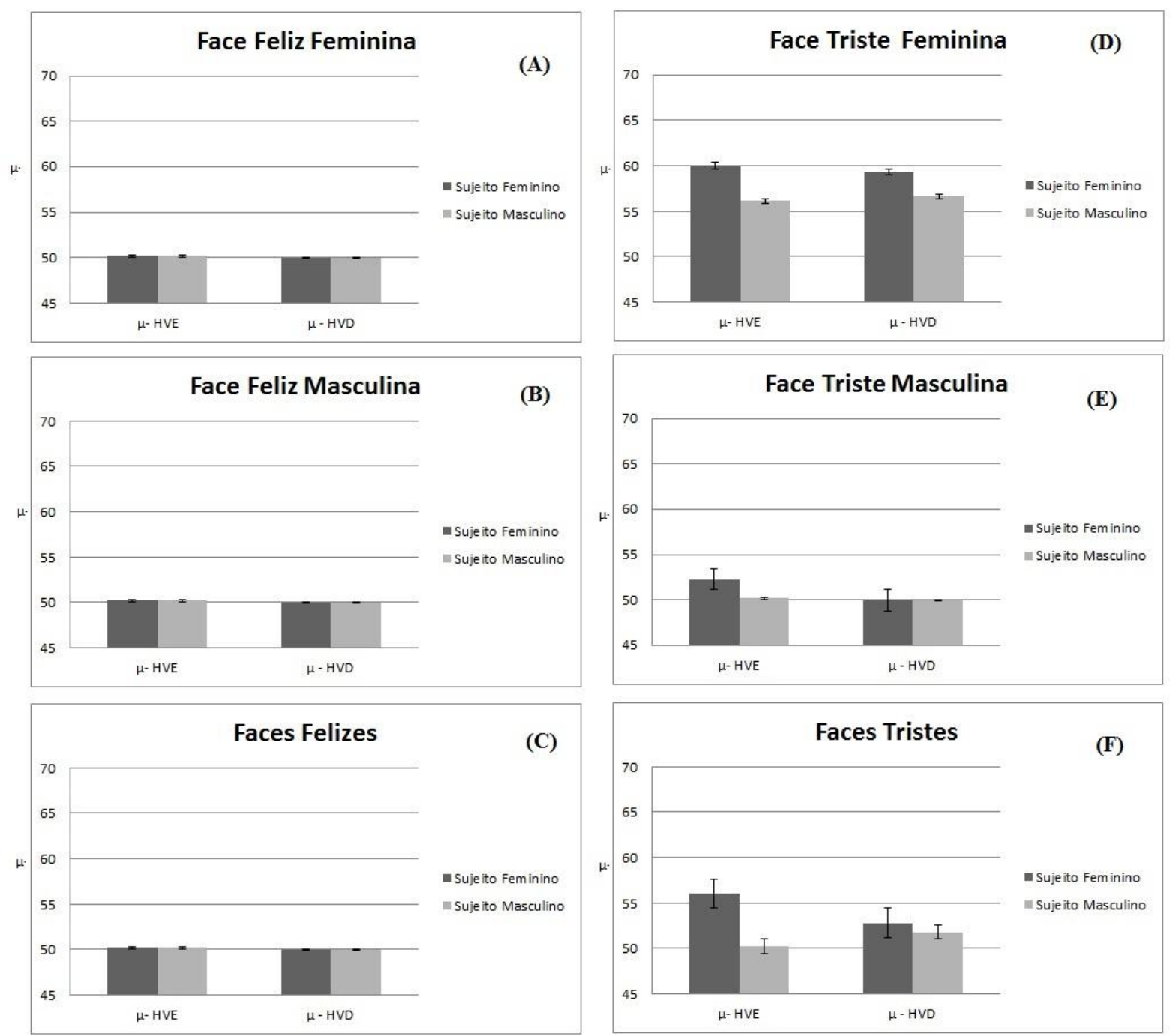

Figura5. Médias e erros padrão do parâmetro $\mu$ para a percepção de (A)Faces Femininas Felizes, (B)Faces Masculinas Felizes, (C)Faces Femininas e Masculinas Felizes, (D)Faces Femininas Tristes, (E)Faces Masculinas Tristes e (F)Faces Femininas e Masculinas Tristes no hemicampo visual esquerdo (HVE) e hemicampo visual direito (HVD).

\subsection{Análise do parâmetro $\sigma$}

Foram repetidos os mesmos procedimentos apresentados anteriormente, considerando, desta vez os dados do parâmetro $\sigma$ : primeiro foi feita análise dos dados de todos os participantes dos dois grupos experimentais e posterior separação dos dados pelo sexo dos participantes (H e M) (anexo 9). 
A análise dos dados de todos os participantes ( $\mathrm{H}$ e $\mathrm{M}$ ) dos dois grupos experimentais (testes com faces tristes e felizes) (ver tabela 1) sugere que faces felizes e tristes não foram reconhecidas da mesma forma $[F(1,22)=4,933 ; p=0,037])$. Observando a figura 5 , é possível verificar essa diferença.

A investigação do parâmetro $\sigma$, que indica a inclinação da curva ou maior discriminação do estímulo permite estabelecer uma relação inversamente proporcional, isto é, quanto maior o valor médio, menor a inclinação da curva.

As faces femininas felizes foram reconhecidas de maneira parecida entre os participantes, porém homens ao observar as faces masculinas felizes e tristes, demonstraram superioridade do hemicampo visual esquerdo, sugerindo maior acurácia do hemisfério cerebral direito no reconhecimento de emoções.

A ANOVA indicou que os homens e as mulheres não reconheceram as faces de forma similar nos hemicampos visuais esquerdo e direito $[F(1,22)=6,857 ; p=0,016]$ e mesmo as emoções de tristeza e felicidade foram reconhecidas diferentemente nos hemicampos visuais direito e esquerdo $[\mathrm{F}(1,22)=7,723 ; \mathrm{p}=0,011]$, (ver Figura 6).

Analisando os participantes em dois grupos distintos (H e M), o grupo masculino mostrou interações estatísticas significativas entre "emoção" e "hemicampo visual" $[\mathrm{F}(1,10)=$ 5,925; $\mathrm{p}=0,035]$, sugerindo que o processamento das faces felizes e tristes no hemicampo visual esquerdo é superior em relação ao direito (ver figura 6).

Analisando as faces felizes, foi observada para os participantes do sexo masculino, interação estatisticamente significativa entre os fatores "sexo da face" e "hemicampo visual" $[F(1,10)=7,959 ; p=0,018]$. Enquanto a face feliz feminina foi melhor reconhecida pelo hemicampo visual direito, a face masculina foi melhor reconhecida pelo hemicampo visual esquerdo. Logo, mulheres apresentaram respostas mais simétricas entre hemicampos visuais, ao passo que homens foram mais assimétricos nos seus julgamentos de faces feminina e masculina felizes.

O mesmo procedimento foi feito em relação ao grupo experimental que julgou faces tristes. O sexo do participante interferiu no reconhecimento dessas faces em relação ao hemicampo visual em que os estímulos foram apresentados. $[F(1,22)=7,982 ; p=0,010]$ mais uma vez demonstrando diferenças entre homens e mulheres. Foram analisados os dados de homens e mulheres separadamente. Os dados dos participantes masculinos demonstraram interação estatística significativa do fator "hemicampo visual" $[\mathrm{F}(1,10)=8,918 ; \mathrm{p}=0,014]$, ao passo que mulheres não apresentaram nenhuma diferença entre os fatores intra sujeitos. 
Homens julgaram faces tristes mais acuradamente quando estas eram mostradas no hemicampo visual esquerdo, a face masculina em particular.
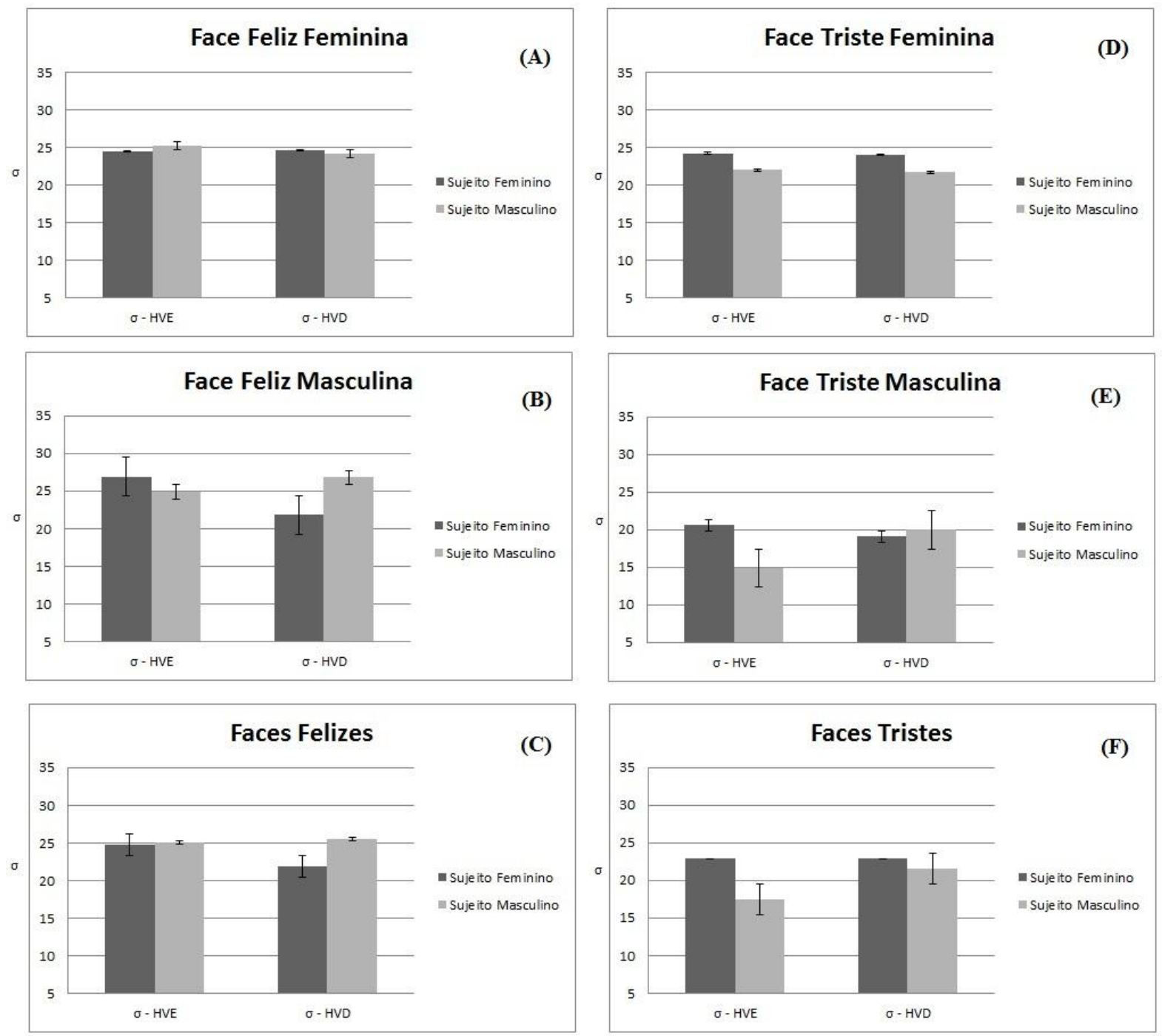

Figura 6. Médias e erros padrão parâmetro $\sigma$ para a percepção de (A)Faces Felizes Femininas, (B)Faces Felizes Masculinas, (C) Faces Felizes Femininas e Masculinas, (D)Faces Tristes Femininas, (E)Faces Tristes Masculinas e (F)Faces Tristes Femininas e Masculinas nos hemicampo visual esquerdo (HVE).

hemicampo visual direito (HVD).

\subsection{Análise do parâmetro $\lambda$}

Da mesma forma que foram apresentados e analisados os dados para os parâmetros anteriores, o mesmo foi feito para os dados considerando o parâmetro lambda $-\lambda$ : A taxa de 
erro no julgamento de faces felizes e tristes foram discordantes $[F(1,22)=29,074 ; p<0,001]$, havendo efeito estatístico significativa no "sexo da face" $[\mathrm{F}(1,22)=12,446 ; \mathrm{p}=0,002]$ e "emoção" e "sexo da face" $[\mathrm{F}(1,22)=29,067 ; \mathrm{p}<0,001]$ (ver tabela 7). Mulheres reconheceram diferentemente as faces emocionais feminina e masculina $[\mathrm{F}(1,12)=4,775$; $\mathrm{p}=0,049]$, assim como faces felizes e tristes $[\mathrm{F}(1,12)=10,198 ; \mathrm{p}=0,008]$, apresentando interações estatísticas entre "emoção" e "sexo da face" $\mathrm{F}(1,12)=8,651 ; \mathrm{p}=0,012]$. Homens demonstraram exatamente as mesmas interações com as variáveis "emoção" $[\mathrm{F}(1,10)=$ 18,314; $\mathrm{p}=0,002]$, "sexo da face" $[\mathrm{F}(1,10)=0,024 ; \mathrm{p}=0,024]$ e com as duas variáveis “emoção" e "sexo da face" juntas $[F(1,10)=19,681 ; \mathrm{p}<0,001]$ (ver Tabela 7, anexo 10). Não houve diferenças estatisticamente significativas entre as taxas de erros durante o reconhecimento de faces felizes, sugerindo que ambos, homens e mulheres, possuem limite de acertos reais similares em relação à face feliz apresentada (ver Tabela 8, anexo 10).

O mesmo foi observado ao desmembrar a análise em conformidade com o sexo dos participantes. Homens e mulheres apresentaram valores $\mathrm{p}>0,05$ quando os fatores "sexo da face", "hemicampo visual" foram avaliados. O oposto ocorreu quando as faces tristes foram submetidas ao mesmo exame. Os julgamentos de homens e mulheres apresentaram interações estatisticamente significativas com o fator "sexo da face" $[F(1,22)=20,664 ; p<0,001$. (ver tabela 10, anexo 10)

Portanto, os limiares de acerto ou taxa de erro das faces felizes e tristes não foram os mesmos. Observando a Figura 7 verifica-se que houve menor acerto quando os participantes observaram as faces tristes, em especial a face feminina triste. Ainda na Figura 7, observa-se que o erro foi maior quando os participantes do sexo masculino julgaram faces femininas no hemicampo visual esquerdo. Mulheres também cometeram mais erros ao julgar faces femininas em comparação a face masculina. 

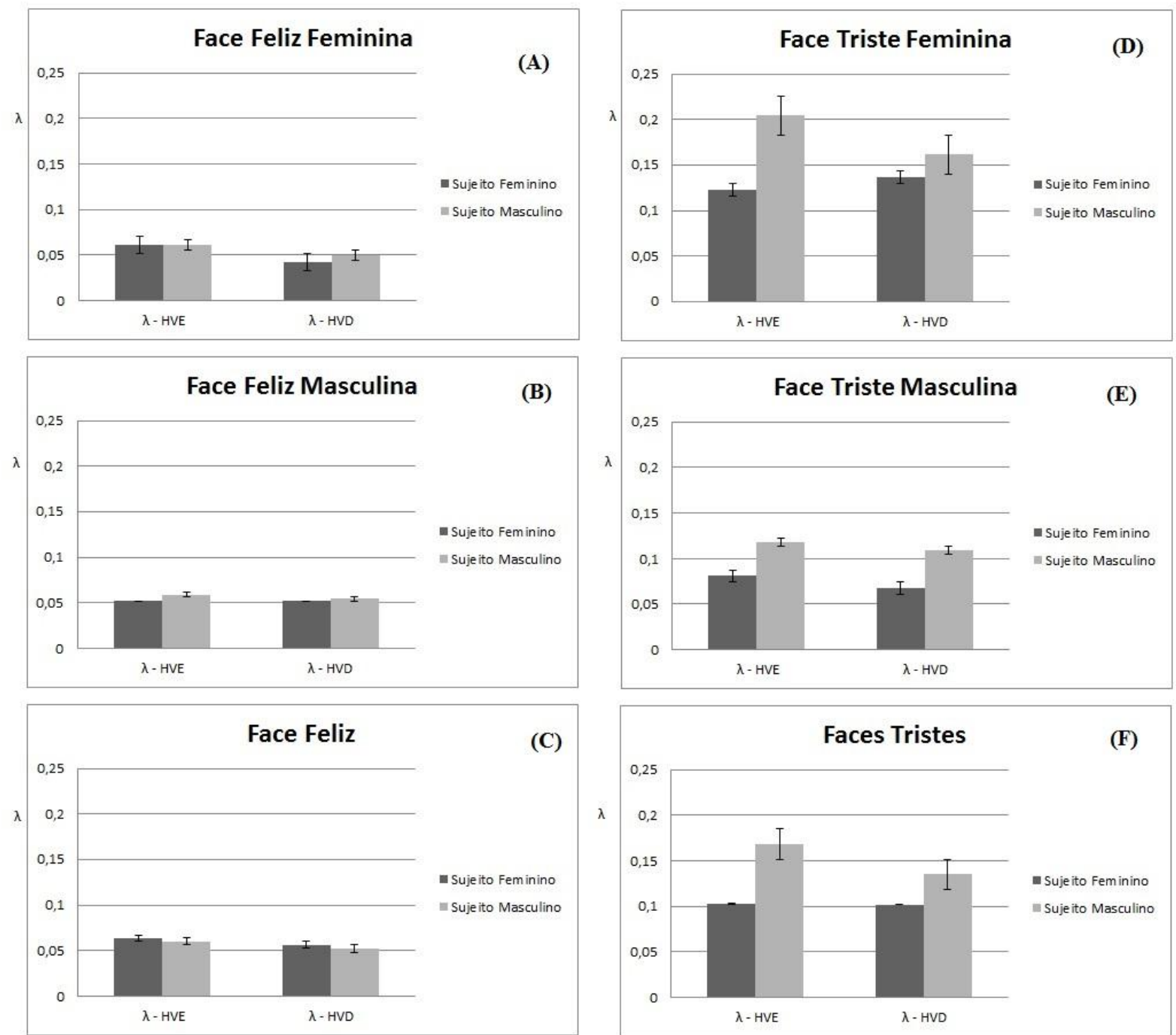

Figura7. Médias e erros padrão parâmetro $\lambda$ para a percepção de (A)Faces Femininas Felizes, (B)Faces Masculinas Felizes, (C)Faces Femininas e Masculinas Tristes, (D)Faces Femininas Tristes, (E)Faces Masculinas Tristes e (F)Faces Tristes Femininas e Masculinas no hemicampo visual esquerdo (HVE) e no hemicampo visual direito (HVD). 


\section{DISCUSSÃO}

A análise dos parâmetros das curvas psicométricas permitiu averiguar que homens são assimétricos, com melhor desempenho hemisfério cerebral direito, enquanto que mulheres são simétricas.

Concordante com alguns trabalhos (Bourne, 2005; Proverbio et al, 2006), os resultados demonstraram que homens são mais lateralizados no processamento de faces, a medida que mulheres são mais bilaterais.

Bourne (2005) sugere duas explicações para este fenômeno. A primeira é que homens possuiriam apenas um mecanismo de processamento facial, e este localiza-se no hemisfério direito do cérebro masculino. Por outro lado, as mulheres, por serem mais bilaterais, possuiriam acesso a mecanismos de ambos os hemisférios cerebrais, o que daria vantagem ao sexo feminino no processamento de faces. Esta alternativa porém, não se encaixa aos resultados encontrados neste estudo, já que mulheres necessitaram maior grau de morphing no reconhecimento das faces, não caracterizando nenhuma vantagem em relação ao sexo masculino.

A segunda explicação é que existem diferenças nas transferências de informação interhemisféricas. Portanto haveria transferência mais eficiente entre os hemisférios cerebrais das mulheres (Bourne, 2005). Porém, nesta pesquisa, os estímulos foram apresentados à cada hemisfério cerebral separadamente, não sendo possível afirmar se esta alternativa é realmente plausível.

Entretanto Grimshaw, Bulman-Fleming e Ngo (2004), em pesquisa utilizando método de detecção de sinaisnão encontram diferenças entre os sexos na percepção de faces com emoções (nomeadamente raiva, medo, felicidade e tristeza).

A diferença entre sexo e assimetria cerebral pode estar relacionada à tarefa utilizada no delineamento experimental. Haussman e Gunturkun (1999) investigaram essas alterações no desempenhodevido à repetição de testes e medidas repetidas. Como consequência foi observado interação entre as repetições e hemisfério cerebral e sexo dos participantes. Os autores sugerem há uma forte influência do número de repetições na assimetria cerebral, afirmando que a acurácia das mulheres diminui a medida que o tempo do teste aumenta, 
principalmente para estímulos apresentados no hemicampo visual esquerdo. Homens, diferentemente, não demonstram essas variações.

Portanto, a lateralização hemisférica encontrada neste estudo pode estar relacionada a quantidade de repetições feitas na sessão experimental. A simetria cerebral apresentada por mulheres pode estar relacionada à diminuição progressiva da acurácia no hemisfério direito, nivelando os dois hemisférios cerebrais no fim do teste.

No presente estudo, a Teoria do Hemisfério Direito, que prevê que o hemisfério cerebral direito é responsável pelo processamento de qualquer estímulo emocional (Borod $e t$ $a l, 1998)$ é parcialmente atestada. Segundo análise do parâmetro $\sigma$, somente o sexo masculino apresentou melhor desempenho do hemicampo visual esquerdo quando os estímulos de faces felizes e tristes foram mostradas. O desempenho da mulheres, que não favoreceu nenhum hemisfério cerebral, na apresentação das duas emoções, não supri nenhuma das teorias.

Nesta pesquisa foi utilizado o método de campo visual divido, que baseia-se no conhecimento prévio de funcionamento do sistema visual, de forma que em condições controladas é possível promover a apresentação dicótica de estímulos visuais (Bourne, 2006).

Segundo Schiffman (2005) o caminho visual feito pela imagem se inicia através do estímulo da imagem no nervo óptico. As vias internas ou nasais entrecruzam-se no quiasma óptico, sendo transferidos para o outro hemisfério cerebral, enquanto os nervos mais externos ou temporais permanecem seu caminho no mesmo hemisfério. Assim, estímulos apresentados em um campo visual seriam processados no hemisfério cerebral oposto.

Resultados advindo da utilização da técnica de fMRI corroboram com a ideia de que é confiável a utilização do método de campo visual dividido para pesquisar lateralizações cerebrais no processamento de informação visual. (Bourne ,2006)

Segundo a revisão feita por Najt, Bayer e Haussmann(2012) a maioria das pesquisas que utilizaram o método de campo visual divido obtiveram resultados que embasavam a Teoria do Hemisfério Direito. Os autores afirmam também que as emoções foram analisadas em combinação, fato que dificulta avaliar a hipótese das valências.

Neste estudo, assim como no de Alves, Aznar-Casanova e Fukusima (2009), foram consideradas as emoções positivas (alegria) e negativas (tristeza) separadamente. Mesmo assim, não foram encontrados resultados que fundamentasse a hipótese das valências.

Ainda, foram utilizadas estímulos de duas faces da coleção de Ekman e Friesen (1976), escolhidas pelo elevado grau de discriminação apresentado. Contudo, houve diferenças entre as faces feminina e masculina. Próximos estudos poderão utilizar diferentes 
faces, afim de considerar se existem diferenças no reconhecimento de faces feminina e masculina.

Todos os participantes discriminaram faces felizes de maneira similar. Para faces triste porém os homens precisaram de menor grau de morphing para discriminar os estímulos. Todos os participantes cometeram mais erros ao julgar faces femininas tristes, com maior taxa de erros sendo das mulheres.

Assim, todos os participantes apresentaram maiores taxas de acertos ao discriminar a face feliz em comparação com a face triste. Duas justificativas podem ser apresentadas embasando-se nesta pesquisa. Primeiro, os componentes móveis da face (boca, sobrancelha, olhos) demonstram uma amplitude maior de deslocamento nas faces felizes. Portanto $20 \%$ de morphinização da face feliz implica uma mudança mais significativa que $20 \%$ da face triste. A segunda justificativa está baseada no melhor reconhecimento de faces felizes em relação às tristes. Kirita e Endo (1995), ao investigar tais diferenças, encontraram vantagem no reconhecimento de faces felizes quando comparadas às faces tristes tanto em faces esquemáticas quanto em faces naturais. Os autores justificam que o reconhecimento de faces pode estar relacionado ao hemicampo visual e tempo de exposição do estímulo, concatenando essas condições com modelos de processamento, favorecendo o reconhecimento da face feliz sob determinadas circunstâncias.

Os resultados deste estudo contribuem para a idéia que existem diferenças no desempenho de homens e mulheres no reconhecimento de faces felizes e tristes. Entretanto, ainda não está claro o porque essas diferenças ocorrem. É necessário uma pesquisa que utilize outros métodos e estímulos afim de investigar mais detalhadamente as hipóteses levantadas nesta discussão.

Também foi possível verificar que faces felizes são melhores discriminadas em relação às faces tristes, possivelmente devido ao tempo de exposição do estímulo ou características configurais das faces.

Por fim, o resultado não embasou nenhuma das teorias de processamento de faces, concordante com o trabalho de Najt, Bayer e Hausmann (2012). Apenas os dados dos participantes do sexo masculino comprovavam a Teoria do Hemisfério Direito. 


\section{CONCLUSÃO}

O presente estudo teve por objetivo investigar a diferença entre o desempenho de homens e mulheres no julgamento de faces felizes e tristes apresentadas nos hemicampos visuais esquerdo e direito.

Por meio dos resultados e discussão dos mesmos foi possível verificar que o método utilizado nesta pesquisa pode influenciar nos resultados e favorecer principalmente a Teoria do Hemisfério Direito (Najt, Bayer, Haussmann,2012; Haussman, Gunturkun, 1999).

Diferenças existentes devido à face estímulo, como sexo da face e componentes móveis e ainda o tempo de exposição do estímulo são outros fatores que devem ser revistos e melhor investigados nas próximas pesquisas.

Portanto, o estudo de assimetria cerebral e diferenças entre os sexos é um assunto complexo, dependente de muitas variáveis. Neste estudo, nomeadamente delineamento experimental, sexo do participante, sexo da face-estímulo, tempo de exposição do estímulo, hemicampo visual e valência da emoção. É importante que tais variáveis sejam consideradas para pesquisas posteriores afim de garantir melhor conhecimento acerca deste tema. 


\section{REFERÊNCIAS}

ABBOTT, J. D. et al. The perception of positive and negative facial expressions by unilateral stroke patients. Brain and Cognition, 2014.

ALVES, N. T. Percepção de emoções faciais de emoção e lateralização cerebral. 2004. 85p. Dissertação (Mestrado em Psicobiologia) - Faculdade de Filosofia, Ciências e Letras de Ribeirão Preto, Ribeirão Preto, 2004.

ALVES, N. T.; FUKUSIMA, S. S.; AZNAR-CASANOVA, J. A. Models of brain asymmetry in emotional processing. Psychology \& Neuroscience, v.1, n.1 p. 63-66, 2008.

ALVES, N. T.; AZNAR-CASANOVA, J. A; FUKUSIMA, S. S..Patterns of brain 31ontour31a in the perception of positive and negative facial expressions. Laterality: Asymetries of Body, Brain and Cognition, n.14, p. 256-272, 2009.

ASSUMPÇÃO JR, FRANCISCO B., et al. Reconhecimento facial e autismo. Arq Neuropsiquiatr 57.4 (1999): 944-949.

BOROD, J. C. et al. Right Hemisphere Emotional Perception: Evidence Across Multiple Channels. Neuropsychology,v. 12, n. 3, p. 446-458, 1998.

BOURNE, V. J. Examining the effects of inversion on lateralization for processing facial emotion. Cortex 47. p.690-695, 2011.

Laterlised Processing of Positive Facial Emotion: Sex Differences in Strength of Hemispheric Dominance. Neuropsychologia, v. 43, p. 953-956, 2005.

The divided visual field paradigm: Methodological Considerations. Laterality, v. 11, n.4, p. $373-393,2006$.

.Examining the Relationship Between Degree of Handedness and Degree of Cerebral Lateralization for Processing Facial Emotion. Neuropsychology , v. 22, n. 3, p.350-356, 2008. 
BOURNE, V. TODD, B. When left means right: an explanation of the left cradling bias in terms of right hemisphere specialisations. Developmental Science, v. 7, p. 19-24, 2004.

BOURNE, V. GRAY, D. Hormone exposure and functional lateralisation: examining the contributions of prenatal and later life hormonal exposure. Psychoneuroendocrinology. V.34, n.8, p.1214-21, 2009.

CARLSON, N. R. Fisiologia do Comportamento, 7. Ed. São Paulo: Manole, 2004.

DARWIN, C. A expressão das emoções no homem e nos animais. Tradução Leon de Souza Lobo Garcia. São Paulo: Companhia das Letras, 2009.

DEMAREE, H. A. et al . Brain Lateralization of Emotional Processing: Historical Roots and a Future Incorporating 'Dominance'’. Behav Cogn Neurosci Rev. v. 4, n. 3, 2005.

EASTWOOD, J. D.; SMILEK, D.; MERIKLE, P. M. Differential attentional guidance by unattended faces expressing positive and negative emotion. Perception \& Psychophysics. V.63, n. 6, p.1004-1013, 2001.

EKMAN, P. All emotions are basic. The Nature of Emotion. Oxford University Press, 1994.

Facial expression and emotion. American Psychologist, v. 48, n.4, p.384-392, 1993.

EKMAN, P.; FRIESEN, W. V. Pictures of facial affect. Palo Alto, CA: Consulting Psychologists Press. 1976

EKMAN, P.; MATSUMOTO, D. R.; FRIESEN, W. V. Facial Expression in Affective Disorders. In Ekman, P.; Rosenberg, E. L. What the face reveals: basic and applied studies of spontaneous expression using the facial action coding system (facs). New Yourk: Oxford Universaty. P.331-342, 1997.

EKMAN, P.; KELTNER, D. Universal facial expressions of emotion: An old controversy and new findings. In U. Segerstrale and P. Molnar (Eds), Where nature meets culture: Nonverbal communication in social interaction ,p. 27 - 46, 1997.

EKMAN, P.; MATSUMOTO, D. R.; FRIESEN, W. V. Facial Expression in Affective Disorders. In Ekman, P.; Rosenberg, E. L. What the face reveals: basic and applied studies of 
spontaneous expression using the facial action coding system (facs). New Yourk: Oxford University. P.331-342, 1997.

ELFENBEIN, H. A.; AMBADY, N. On the universality and cultural specificity of emotion recognition: A meta-analysis. Psychological Bulletin, v 128, n.2,p. 203-235, Mar 2002.

EVERHART, D. E.; HARRISON, D. W.; CREWS, W. D. J. Hemispheric Asymmetry as a Function of Handedness: Perception of Facial Affect Stimuli. Percetual and Motor Skills, v. 82, p. 264-266, 1996.

FRANK, M. G., STENNETT, J. The forced-choice paradigm and the perception of facial expressions of emotion. Journal of Personality and Social Psychology. V.80, n.1, p.75-85, 2001.

FUSAR-POLI, P. et al. Laterality effect on emotional faces processing: ALE meta-analysis of evidence. Neuroscience letters. V.452, n. 3, p.262-7, 2009

GRIMSHAW, G M; BULMAN-FLEMING, M B; NGO, C. A signal-detection analysis of sex differences in the perception of emotional faces. Brain and Cognition. V.54, n. 3, p. 248$250,2004$.

HAUSER, M. D. Right hemisphere dominance for the production of facial expression in monkeys. Science,v. 261, p. 475-477, July 1993.

HAUSMANN, M. GUNTURKUN, O. Sex Differences in Functional Cerebral Asymmetries in a Repeated Measures Design. Brain and Cognition. V.41, p.264-275, 1999.

HAXBY, J. V.; HOFFMAN, E. A.; GOBBINI, M. I. The distributed human neural system for face perception. Trendsin Cognitive Sciences. V . 4, n . 6, jun. 2000

ISHAI, A.; SCHMIDT ,C. F.; BOESIGER, P. Face perception is mediated by a distributed cortical network. Brain Research Bulletin ,v. 67, p. 87-93, 2005.

KANWISHER, N.; MCDERMOTT, J.; CHUUN, M. M. The Fusiform Face Area: A Module in Human Extrastriate Cortex Specialized for Face Perception. The Journal of Neuroscience,v. 17, n. 11, p. 4302-4311, June 1997.

KIRITA, T. ENDO, M. Happy face advantage in recognizing facial expressions. Acta Psychologica, n. 89,p.149-163,1995. 
KILLGORE, W.D.S.; YURGELUN-TODD, D.A. Sex-related developmental differences in the lateralized activation of the prefrontal cortex and amygdala during perception of facial affect. Perceptual e Motor Skills, v.99, p. 371-391, 2004.

Activation of the amygdala and anterior cingulate during nonconscious processing of sad versus happy faces. NeuroImage. v.21, n.4, p.1215-23, 2004.

KLEIN, S. A. Measuring, estimating, and understanding the psychometric function: A commentary .Perception \& Psychophysics, v.63, n.8, p.1421-1455, 2001

LEE, T.M. C. et al. Gender differences in neural correlates of recognition of happy and sad faces in humans assessed by functional magnetic resonance imaging. Neuroscience Letters, v.333, n.1, p.13-16, 2002.

LIU, L.; IOANNIDES, A. A. Emotion Separation is Completed Early and it depends on Visual Field Presentation. PloS ONE. v.5, n.3, March 2010.

MCCLURE, E. B. et al. Facial Expression Recognition in Adolescents With Mood and Anxiety Disorders. Am J Psychiatry, v. 160, p.1172-1174, 2003.

MURRAY, A. D. Infant Crying as an Elicitor of Parental Behavior: An Examination of Two Models. Psychological Bulletin. Sidney, v. 86, n. 1, p.191-215, 1979.

NAJT, P. BAYER, U. HAUSSMANN, M. Models of Hemispheric Specialization in Facial Emotion Perception - A Reevaluation. Emotion. p. 1-9, 2012.

OLDFIELD, R. C. The assessment and analysis of handedness: The Edinburgh inventory. Neuropsychologia, v.9, p. 97-113, 1971.

OU, J. Facial Expression Recognition Analysis with Muti-Scale Filter. Physics Procedia, v. 25, p. $1236-1240,2012$.

PESSOA, L. et al. Neural processing of emotional faces requires attention. Proceedings of the National Academy of Sciences of the United States of America. v.99, n.17, p. 1145863, 2002. 
PHILLIPS, M. L. et al. Investigation of Facial Recognition memory and Happy and Sad Facial Expression Perception: an fMRI study. Psychiatry Research: Neuroimaging Section v.83, p. 127-138, 1998.

PROVERBIO, A. M. et al. Gender differences in hemispheric asymmetry for face processing. BMC Neuroscience. v.7, n.44, 2006.

ROBINSON, R. G. Lateralized behavioural and neurochemical consequences of unilateral brain injury in rats. In S. D. Glick (Ed.), Cerebral lateralization in nonhuman species. p.135-156, 1985.

SATO, W., AOKI, S. Right hemispheric dominance in processing of unconscious negative emotion. Brain and Cognition ,v.62, p. 261-266, 2006.

SCHIFFMAN, H. R. Sensação e Percepção. 5 ed. Rio de Janeiro: LTC, 2005.

WAGER, T. D. et al. Valence, gender, and lateralization of functional brain anatomy in emotion: a meta-analysis of findings from neuroimaging. NeuroImage , v.19 , p. 513-531, 2003.

WALlRAVEN, C., CUNNINGHAM, D. W. Experimental Design From User Studies to Psychophysics. A K Peters/CRC Press, 2011. 
Anexos 


\section{Anexo1}

Termo de Consentimento Livre e Esclarecido

Esta pesquisa é intitulada "Assimetrias nos reconhecimentos de expressões faciais entre hemicampos visuais de homens e mulheres" e seu objetivo é investigar se as pessoas conseguem reconhecer expressões faciais de alegria e tristeza com diferentes intensidades apresentadas nos campos visuais esquerdo e direito.

Esta pesquisa justifica-se porque auxilia no entendimento do reconhecimento de expressões faciais de emoções, processo que ainda não está totalmente claro e que possui relevância nas interações sociais dos indivíduos.

Você será submetido a uma sessão experimental, individualmente, que durará aproximadamente 40 minutos. Nessa sessão você deverá manter o olhar fixo no centro da tela do computador e logo em seguida lhe serão apresentadas, rápida e sucessivamente, nas laterais direita ou esquerda da tela, imagens de duas faces, uma com e outra sem expressão emocional de tristeza ou alegria. A sua tarefa será indicar se a face com expressão emocional foi a primeira ou a segunda face apresentada.

Para saber se você entendeu a tarefa, iremos inicialmente fazê-la por algumas vezes como treino.

É importante que você complete a sessão experimental, entretanto, se você quiser desistir de participar da pesquisa, você poderá fazer isso em qualquer momento sem quaisquer penalizações ou ônus.

Lembramos que nesta pesquisa não há riscos que venham 37ontour37a-lo(a) quanto a sua integridade física ou mental.

Estamos somente interessados nos resultados da pesquisa, e se os mesmos forem apresentados em publicações ou reuniões científicas, ou em quaisquer outras circunstâncias, sua identidade será sempre mantida em sigilo.

Caso tenha algum gasto decorrente da participação desta pesquisa (com transporte, por exemplo) você será ressarcido.

Você receberá uma cópia deste TCLE e poderá entrar em contato com o pesquisador sempre que achar conveniente para esclarecimentos.

Declaro que estou ciente das informações acima e desejo participar desta pesquisa.

Local e Data:

Nome do Participante:

Nome do Pesquisador:

Assinatura do Participante:

Assinatura:

E-mail do pesquisador:

Orientando: Maria Elisa Kusano

Orientador: Prof. Dr. Sérgio Sheiji Fukusima

Endereço: Av. Bandeirantes, 3900. Bairro: Monte Alegre. Cep. 14.040-901. Ribeirão Preto - SP. Universidade de São Paulo - Faculdade de Filosofia, Ciências e Letras. Departamento de Psicologia e Educação. Telefone (16) 3602 -3729. 
Anexo 2- Inventário de Dominância Lateral de Edimburgo (Oldfield, 1971)

Nome:

Data de Nascimento:

Sexo:

Por favor, indique sua preferência no uso das mãos nas seguintes atividades colocando o sinal + na coluna apropriada. Onde a preferência é tão forte que você nunca usaria a outra mão a menos que fosse forçado a usá-la, coloque ++ . Se em algum caso a mão utilizada é realmente indiferente, coloque $+\mathrm{em}$ ambas as colunas.

Algumas das atividades requerem as duas mãos. Nestes casos a parte da tarefa, ou objeto, para a qual a preferência manual é solicitada é indicada entre parênteses.

Por favor, tente responder todas as questões, e somente deixe em branco se você não tiver qualquer experiência com o objeto ou tarefa.

Você já teve alguma tendência a ser canhoto? Sim Não

Corrigir esse formulário - falta o item 1 abaixo

\begin{tabular}{|l|l|l|}
\hline & Esquerda & Direita \\
\hline $\mathbf{1}$ Escrever & & \\
\hline $\mathbf{3}$ Arremessar & & \\
\hline $\mathbf{5}$ Uso de tesouras & & \\
\hline 6 Uso de faca (sem garfo) & & \\
\hline $\mathbf{7}$ Uso de colher & & \\
\hline $\mathbf{8}$ Uso de vassoura (mão superior) & & \\
\hline $\mathbf{9}$ Acender um fósforo (mão do fósforo) & & \\
\hline 10 Abrir uma caixa (mão da tampa) & & \\
\hline 11 Uso de pente & & \\
\hline 12 Uso de martelo & & \\
\hline 13 Uso de chave de fenda & & \\
\hline 14 Distribuir cartas (carta sendo distribuída) & & \\
\hline 15 Colocar linha no buraco da agulha (linha ou agulha de & & \\
\hline acordo com qual delas é movimentada) & & \\
\hline 16 Qual olho você usa quando está usando apenas um? & & \\
\hline
\end{tabular}




\section{Anexo 3}

As seguintes instruções serão dadas antes do início da sessão:

“Antes de iniciar o experimento eu vou posicioná-lo(a) na frente deste computador. É muito importante que você não saia desta posição durante o teste. Caso você tenha algum problema poderá me chamar."

Após o posicionamento adequado, as orientações continuarão:

"Agora você está na posição correta para realizar o teste. Enquanto olha o mais fixamente possível para o ponto no centro da tela (mostra o ponto de fixação com o dedo), a sua tarefa será identificar qual das duas faces que serão mostradas contém expressão emocional. Se você achar que a primeira face mostrada tem expressão de emoção, aperte o número 1, se achar que foi a segunda face aperte o número 2 (haverá uma pausa e demonstração da apresentação na tela do computador).

Você deverá sempre usar a mão direita. As faces poderão aparecer tanto do lado direito quanto do esquerdo da tela como você pôde ver. Antes de iniciar o teste vamos fazer um treino para garantir que você entendeu. Caso tenha alguma dúvida faremos mais tentativas de treino. Essas são as teclas que você deverá pressionar (aponta para as teclas $1 \mathrm{e}$ 2). Você poderá fazer as pausas entre uma tentativa e outra, após ter dado a resposta. Quando aparecer essa tela (mostra a tela com o ponto de fixação) você poderá esperar até se sentir à vontade para continuar a responder os testes. Podemos começar o treino?"

Será feito um treino com 5 tentativas, supervisionadas pelo experimentador.O experimentador questionará o participante para garantir que a tarefa foi compreendida:

"Você entendeu? Gostaria de repetir o treino?"

Caso a tarefa não seja entendida, esta será explicada novamente e mais treinos serão feitos. Quando o participante estiver apto, o experimentador sairá da sala dizendo “Agora começaremos os testes, que serão divididos em duas partes, de aproximadamente 20 minutos 
cada. Você pode escolher o melhor horário para fazer o segundo teste. Caso ache necessário e se sinta cansado(a) durante o teste, você poderá fazer as pausas. Tente responder da forma mais correta possível. Assim que as tentativas cessarem, ou caso haja algum problema por favor me chame." 
Anexo

\section{FACULDADE DE FILOSOFIA, CIÊNCIAS E LETRAS DE RIBEIRÃO PRETO- USP}

\section{PARECER CONSUBSTANCIADO DO CEP}

DADOS DO PROJETO DE PESQUISA

Título da Pesquisa: Assimetrias nos reconhecimentos de expressões faciais entre hemicampos visuais de homens e mulheres

Pesquisador: Maria Elisa Kusano

Área Temática:

Versão: 2

CAAE: 13851213.7 .0000 .5407

Instituição Proponente: Faculdade de Filosofia, Ciências e Letras de Ribeirão Preto- USP

Patrocinador Principal: Coordenação de Aperfeiçoamento de Pessoal de Nível Superior ((CAPES))

DADOS DO PARECER

Número do Parecer: 276.237

Data da Relatoria: $16 / 05 / 2013$

Apresentação do Projeto:

Sem alterações (vide versão 1)

Objetivo da Pesquisa:

Sem alterações (vide versão 1)

Avaliação dos Riscos e Benefícios:

Sem alterações (vide versão 1)

Comentários e Consideraçöes sobre a Pesquisa:

Os pontos levantados no 10 parecer forma devidamente explicados ou modificados pela pesquisadora, tendo sido incorporados ao Projeto. Não vejo qualquer outro aspecto

nesse projeto que pareça conflitar com as diretrizes éticas básicas para a pesquisa com seres humanos.

Considerações sobre os Termos de apresentação obrigatória:

Sem alterações (vide versão 1)

Recomendações:

Nenhuma.

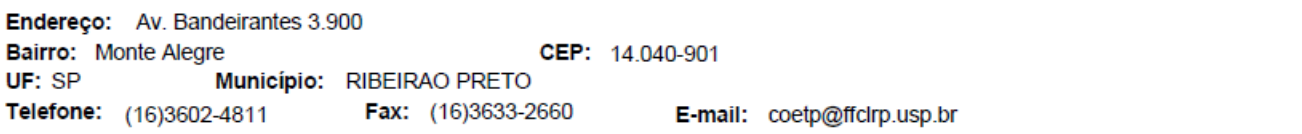




\section{FACULDADE DE FILOSOFIA, CIÊNCIAS E LETRAS DE RIBEIRÃO PRETO- USP

Continuação do Parecer: 276.237

\section{Conclusões ou Pendências e Lista de Inadequaçöes:}

Projeto Ok. Sugiro aprovação no CE.

Situação do Parecer:

Aprovado

Necessita Apreciação da CONEP:

Não

Consideraçöes Finais a critério do CEP:

O projeto encontra-se APROVADO para execução. Pedimos atenção aos seguintes itens:

1) De acordo com o item VII.13.d, da Resolução CNS n. ${ }^{\circ}$ 196/96, o pesquisador deverá apresentar relatórios anuais (parciais ou finais, em função da duração da pesquisa) para o CEP;

2) Eventuais emendas (modificações) ao protocolo devem ser apresentadas, com justificativa, ao CEP de forma clara e sucinta, identificando a parte do protocolo a ser modificada;

3) Sobre o TCLE: caso o termo tenha DUAS páginas ou mais, lembramos que no momento da sua assinatura, tanto o participante da pesquisa (ou seu representante legal) quanto o pesquisador responsável deverão RUBRICAR todas as folhas, colocando as assinaturas na última página.

RIBEIRAO PRETO, 20 de Maio de 2013

Assinador por:

Andréia Schmidt

(Coordenador)

Endereço: Av. Bandeirantes 3.900

Bairro: Monte Alegre

UF: SP Município: RIBEIRAO PRETO

Telefone: (16)3602-4811 Fax: (16)3633-2660

CEP: $14.040-901$

E-mail: coetp@ffclrp.usp.br 
Anexo 5 - Fotografias utilizadas na composição dos estímulos para o experimento.
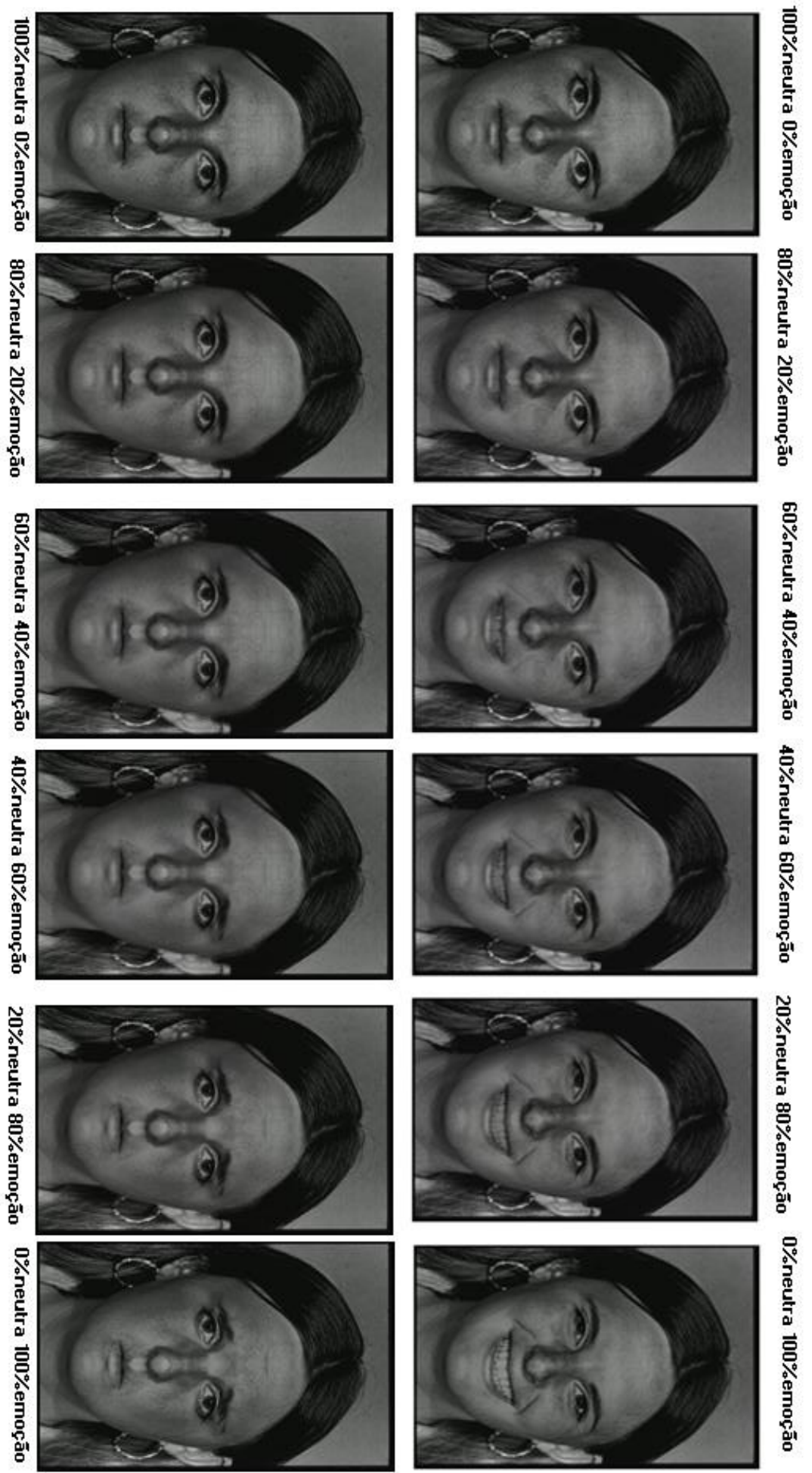

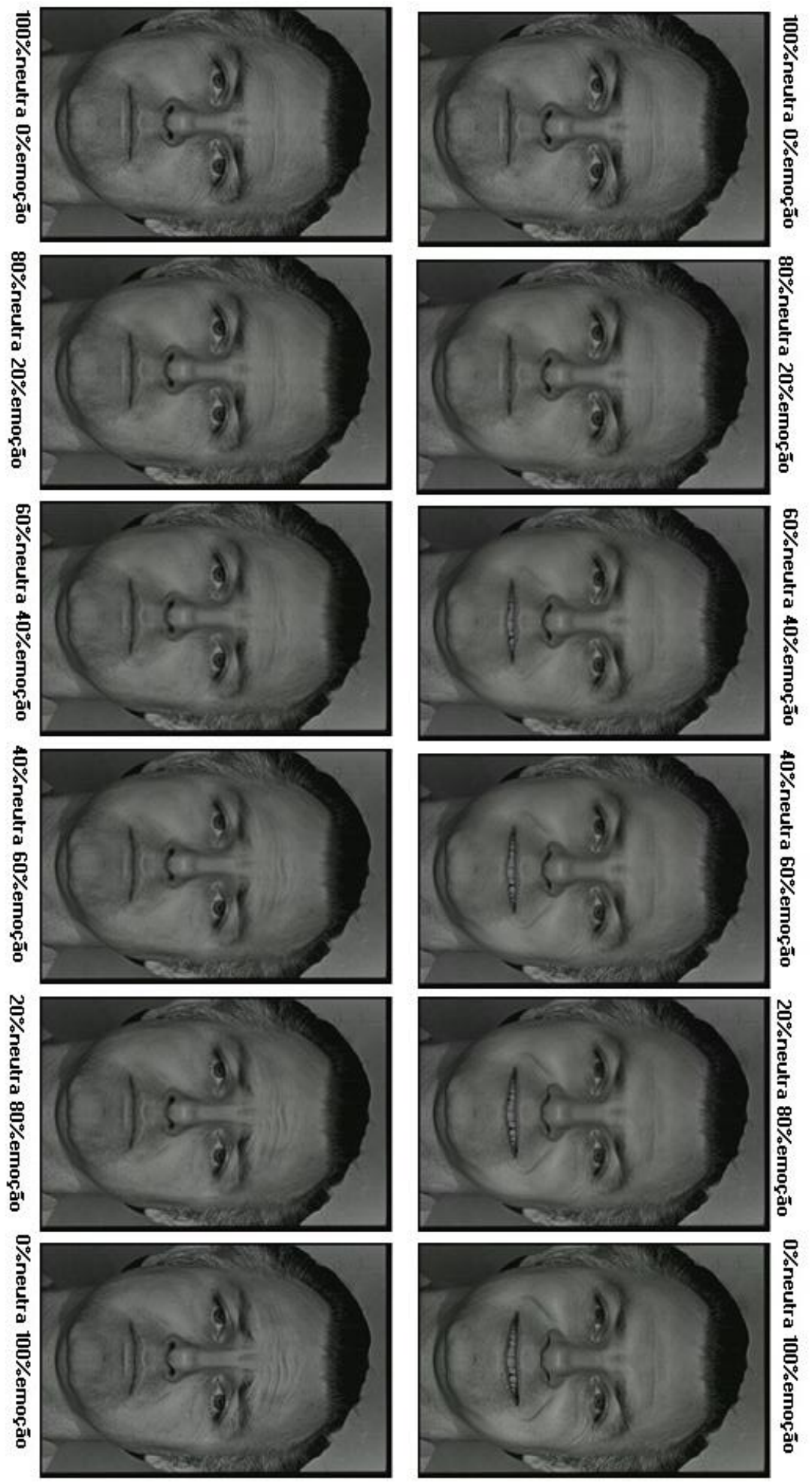


\section{Anexo 6 - Script do Programa Matlab utilizado para estimar parâmetros da curva psicométrica.}

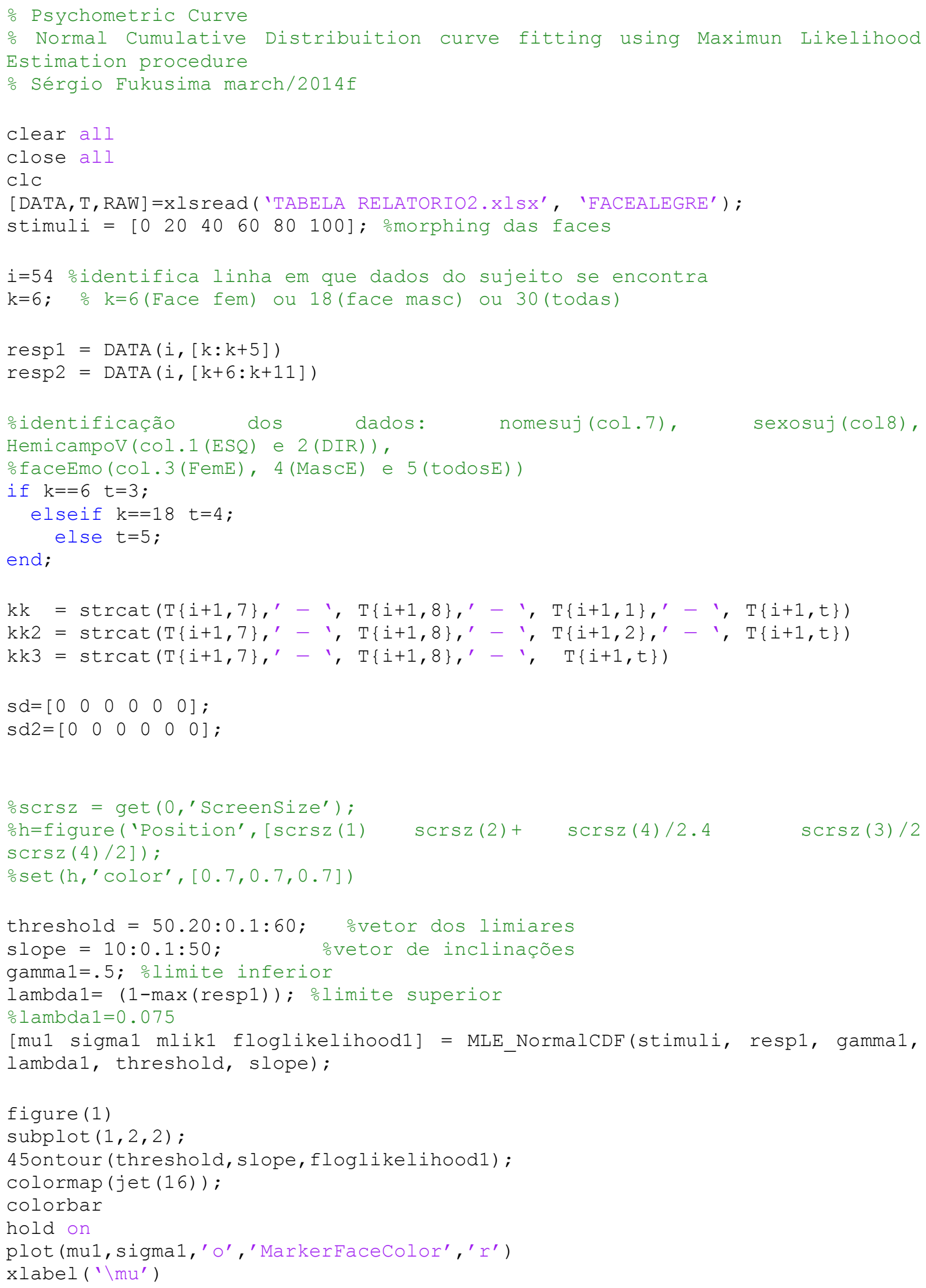


ylabel ( '\sigma')

title('Log-likelihood for Normal Distribuition Parameters')

axis square

hold off

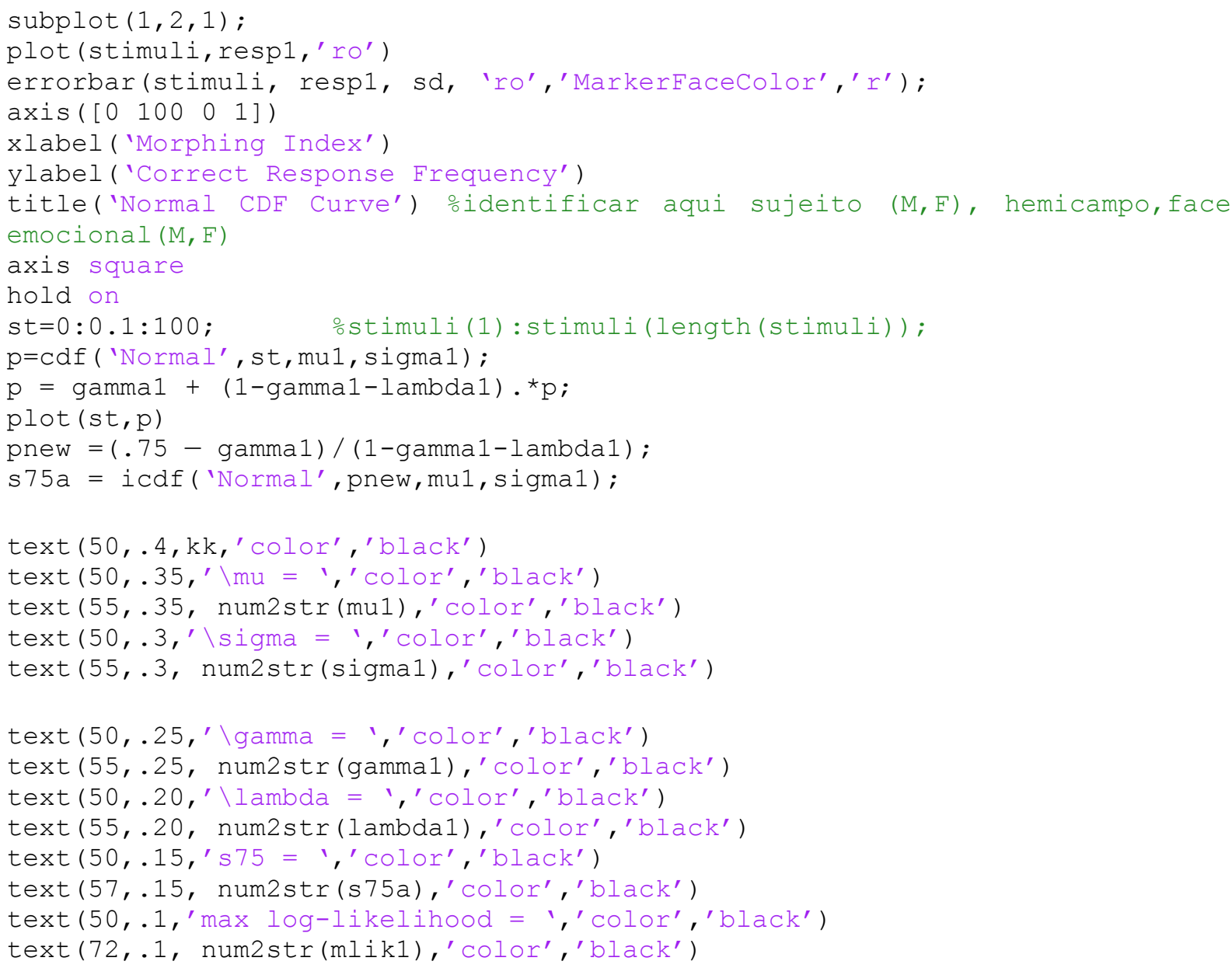


hold on

plot (mu2, sigma2,' 'o', 'MarkerFaceColor', ' r' )

xlabel ('\mu')

ylabel ('\sigma')

title('Log-likelihood for Normal Distribuition Parameters')

axis square

hold off

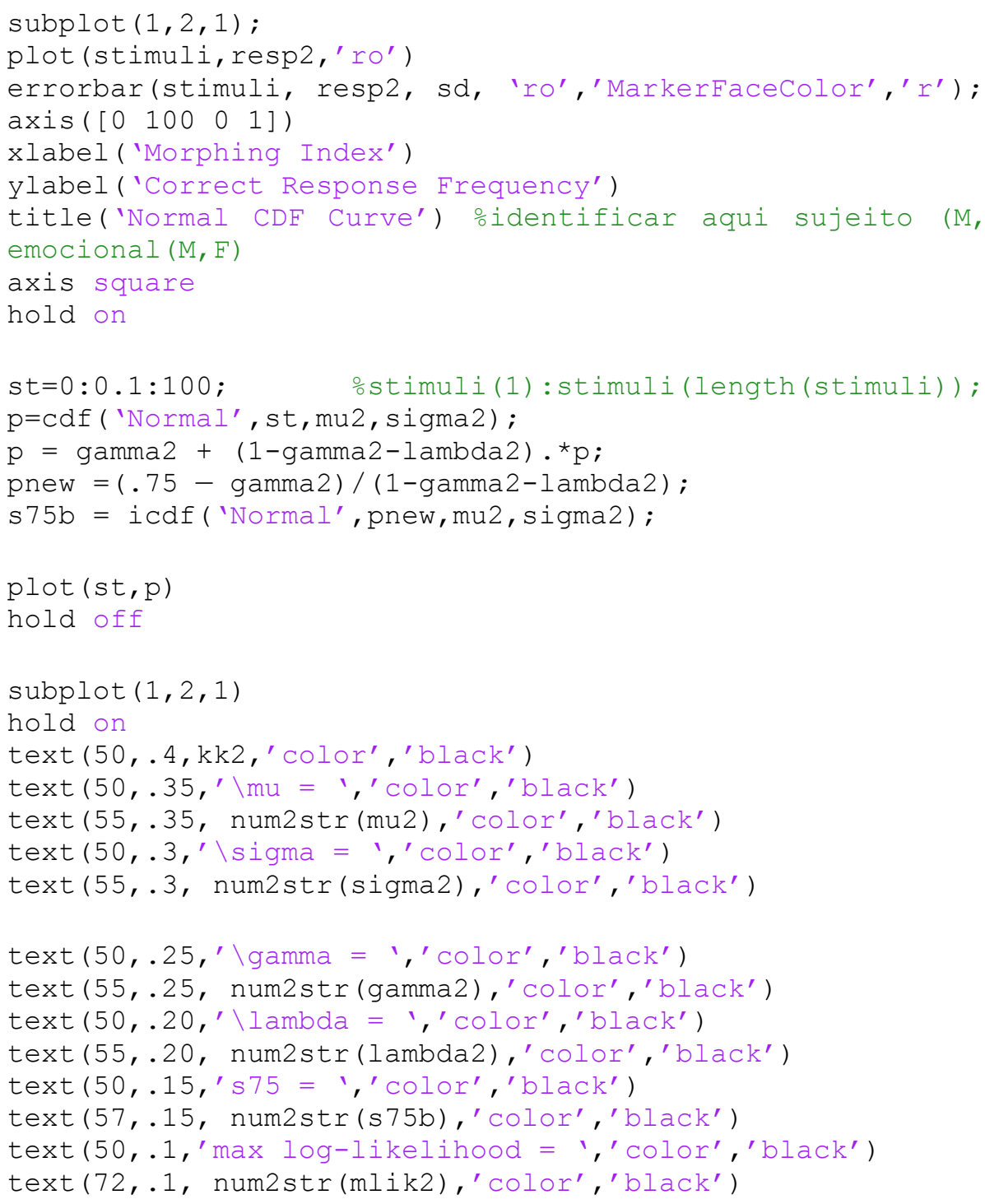




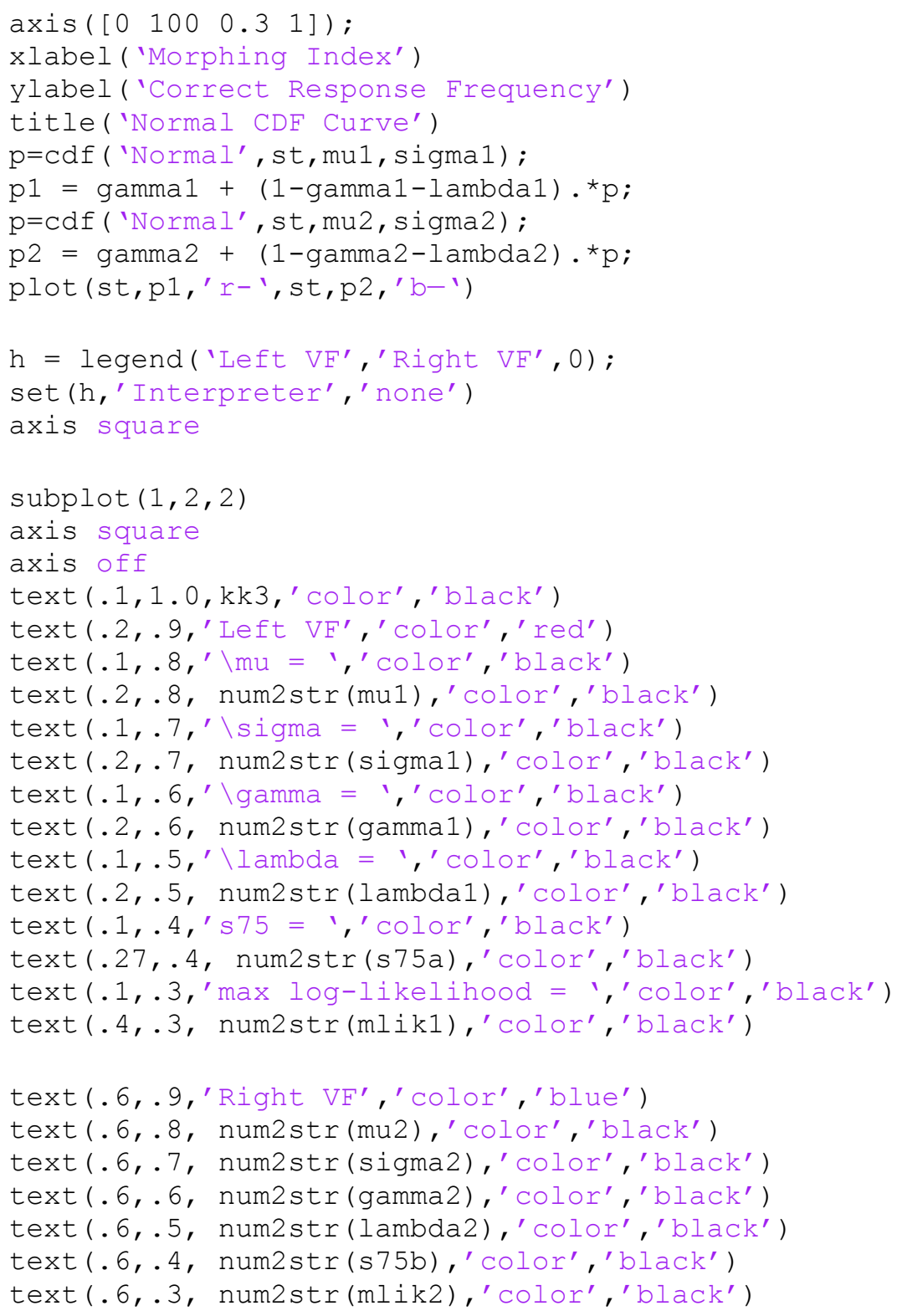




\section{Anexo 7 - Dados Gerais dos Participantes}

Tabela com dados de homens e mulheres e os estímulos de faces felizes

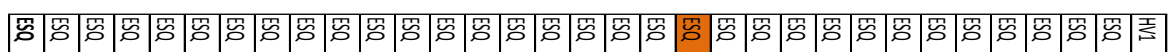

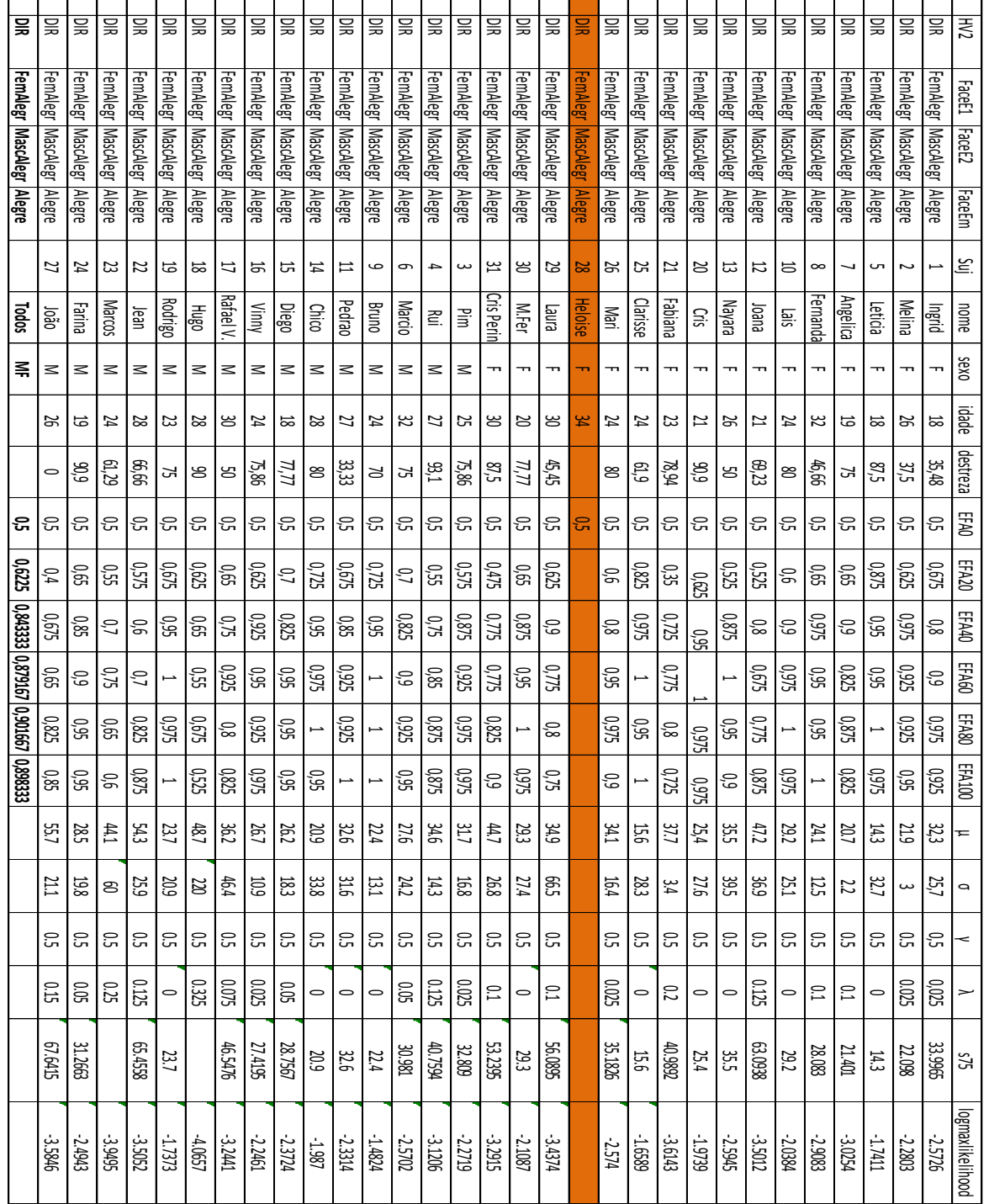




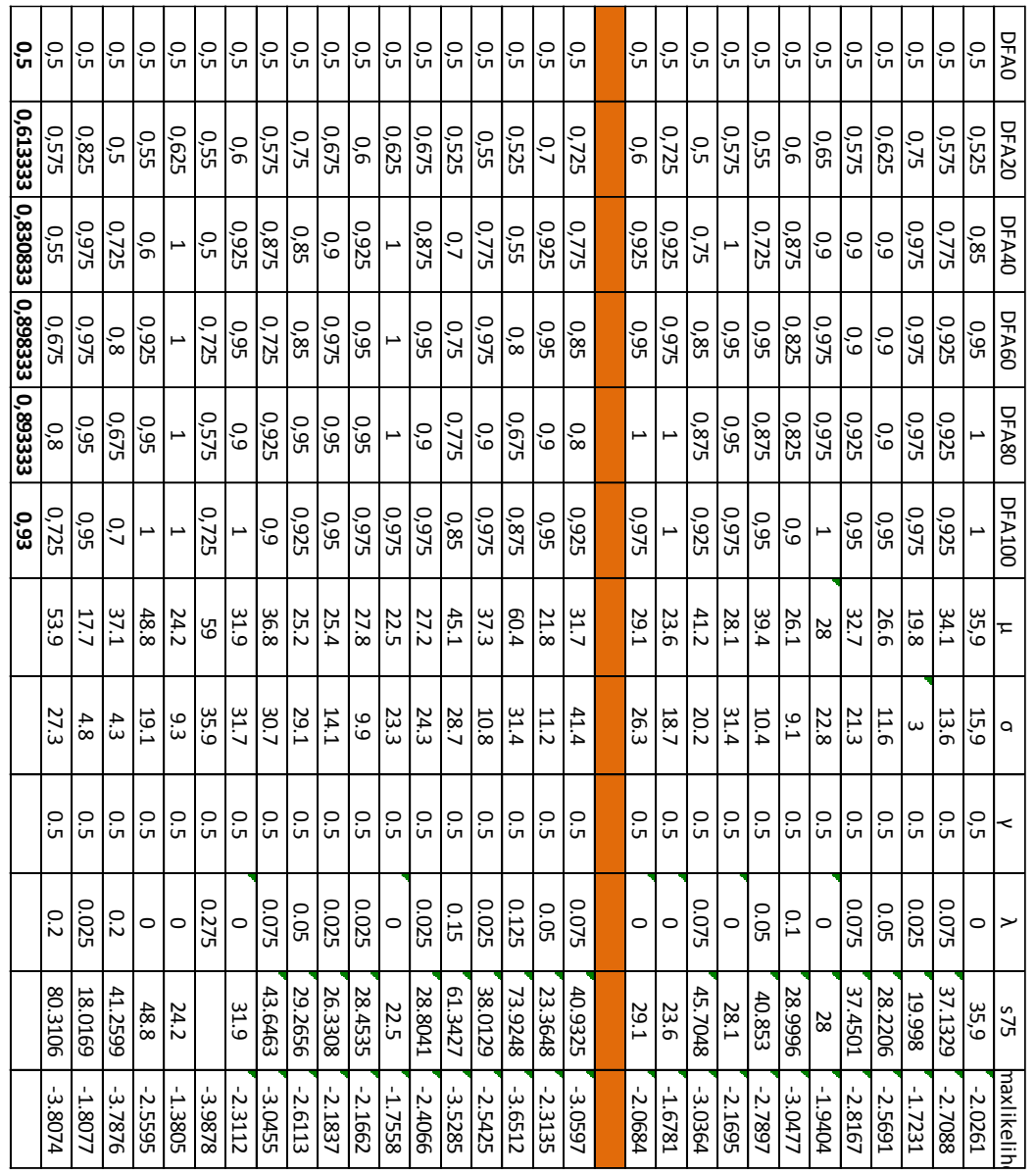

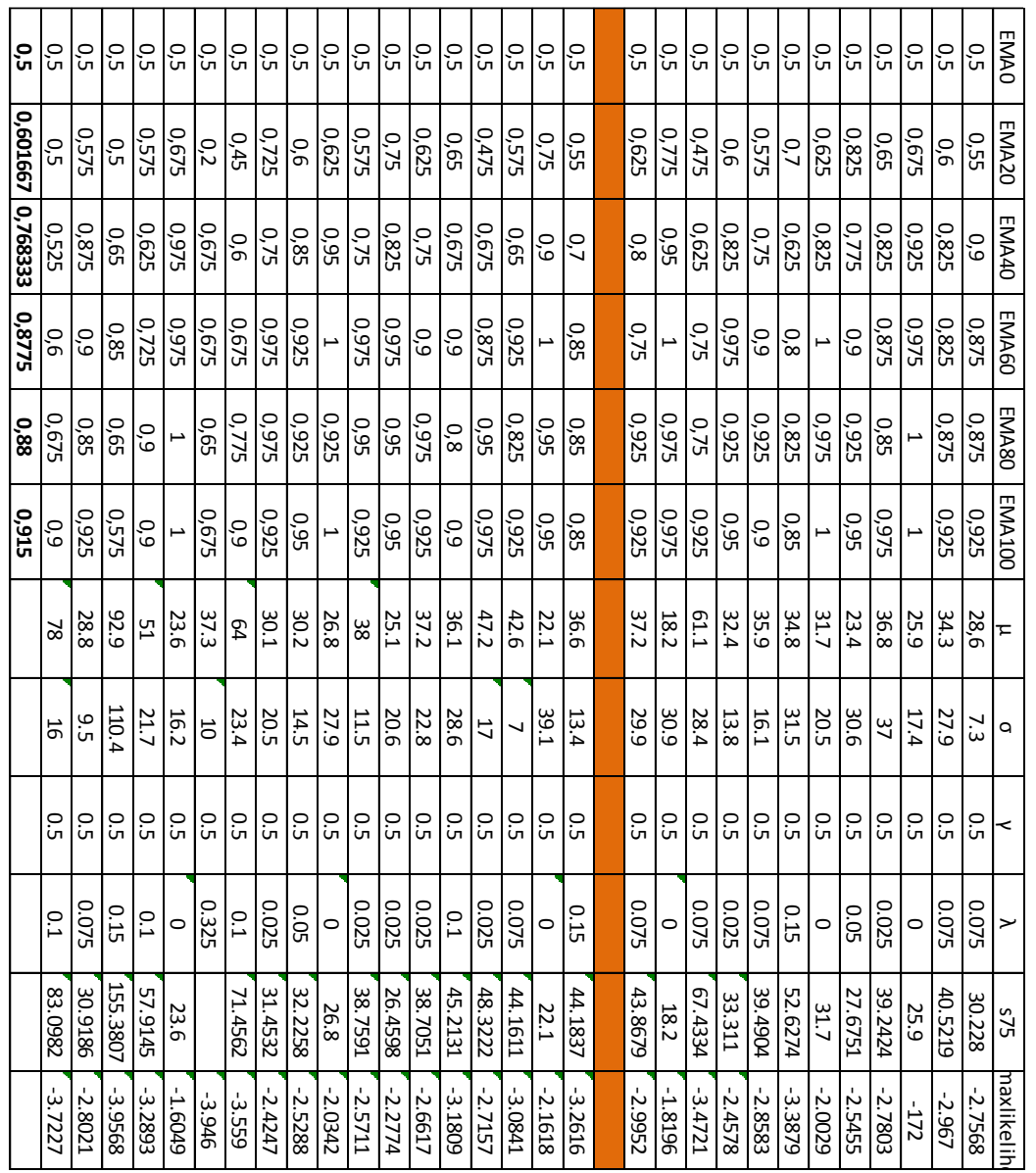




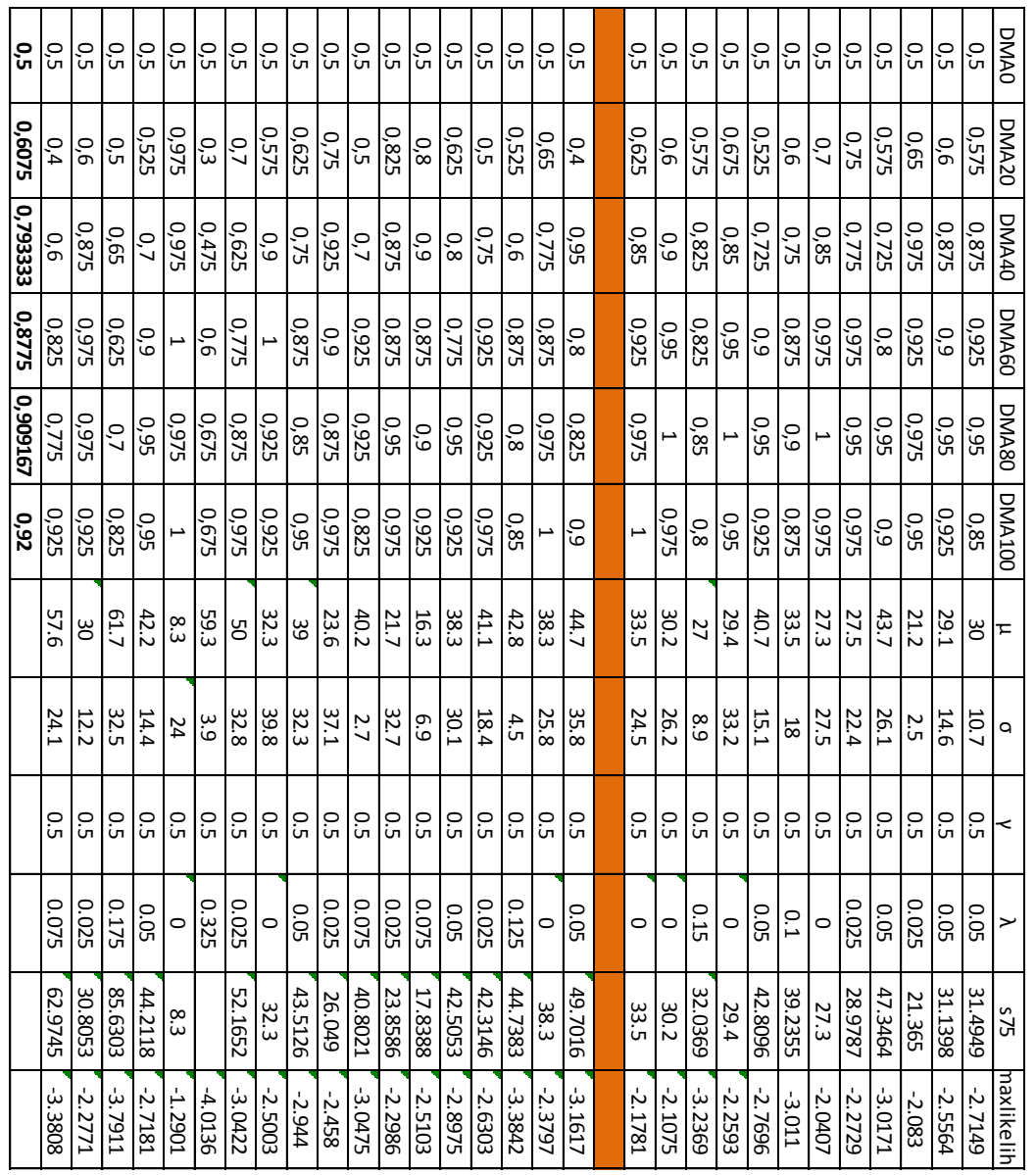

\begin{tabular}{|c|c|c|c|c|c|c|c|c|c|c|c|c|c|c|c|}
\hline & iv & $\mathrm{in}$ & in & in [iv & 放 & 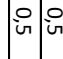 & iv & Fin & & & in & & & & 罗 \\
\hline 哈 & & & & & 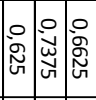 & & & $\mid$ & 哯 & & 象 & & & & 思罢 \\
\hline 总 & & & & & 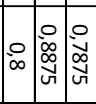 & & 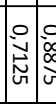 & $\infty$ & $\infty$ & 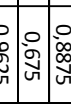 & \begin{tabular}{|l|l}
$\circ$ \\
0 \\
0 \\
0 \\
0
\end{tabular} & $\begin{array}{l}0 \\
0\end{array}$ & 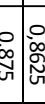 & & $\begin{array}{l}n=1 \\
0\end{array}$ \\
\hline & & & & & & & {$\left[\begin{array}{ccc}0 & \\
0 \\
0 \\
0\end{array}\right]$} & $\mid$ & $\left|\begin{array}{l}0 \\
\infty \\
0 \\
\vdots\end{array}\right|$ & 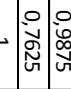 & : & & & 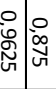 & 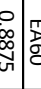 \\
\hline & & & & & & & $\begin{array}{lll}0 & 0 \\
0 & 0 \\
0 & 0 & 0 \\
0\end{array}$ & 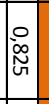 & : & & | & 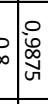 & 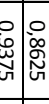 & & $\stackrel{5}{5}$ \\
\hline & $v$ & & & & & $\mid \begin{array}{lll}0 & 0 \\
0 & 0 \\
0 & 0 \\
0 & 0 \\
ن & 0\end{array}$ & & 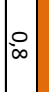 & 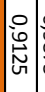 & & $: 0$ & 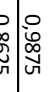 & : & 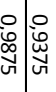 & 罯 \\
\hline & 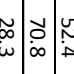 & & $\begin{array}{cc}\vec{\omega} \\
\vec{\omega} & \tilde{N}\end{array}$ & & & & $\mid \begin{array}{l}\hat{u} \\
\dot{H}\end{array}$ & $\tilde{\Omega}$ & $\mid \begin{array}{l}w \\
\substack{w \\
\sim}\end{array}$ & & 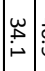 & 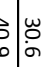 & $N$ & & 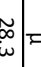 \\
\hline & 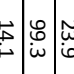 & & & & 代芯 & & $\tilde{v}$ & $|\infty|$ & $\left|\begin{array}{c}\tilde{N} \\
\dot{\infty}\end{array}\right|$ & 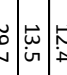 & 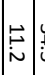 & 象 & ה. & & \\
\hline & in & & & & & & & & in & & & & & & \\
\hline $\mathbb{N}$ & 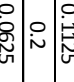 & & & & 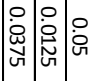 & & 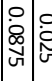 & & i. & $\begin{array}{c}0 \\
0\end{array}$ & & & & ○唏 & \\
\hline & 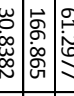 & & & 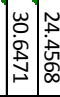 & 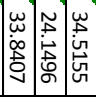 & & & & $\left|\begin{array}{l}w \\
\infty \\
0 \\
0 \\
\infty \\
\infty\end{array}\right|$ & 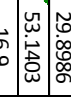 & & 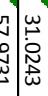 & & 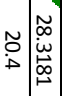 & \\
\hline & & & & & & & & & $\mid$ & & & & & 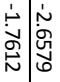 & \\
\hline
\end{tabular}




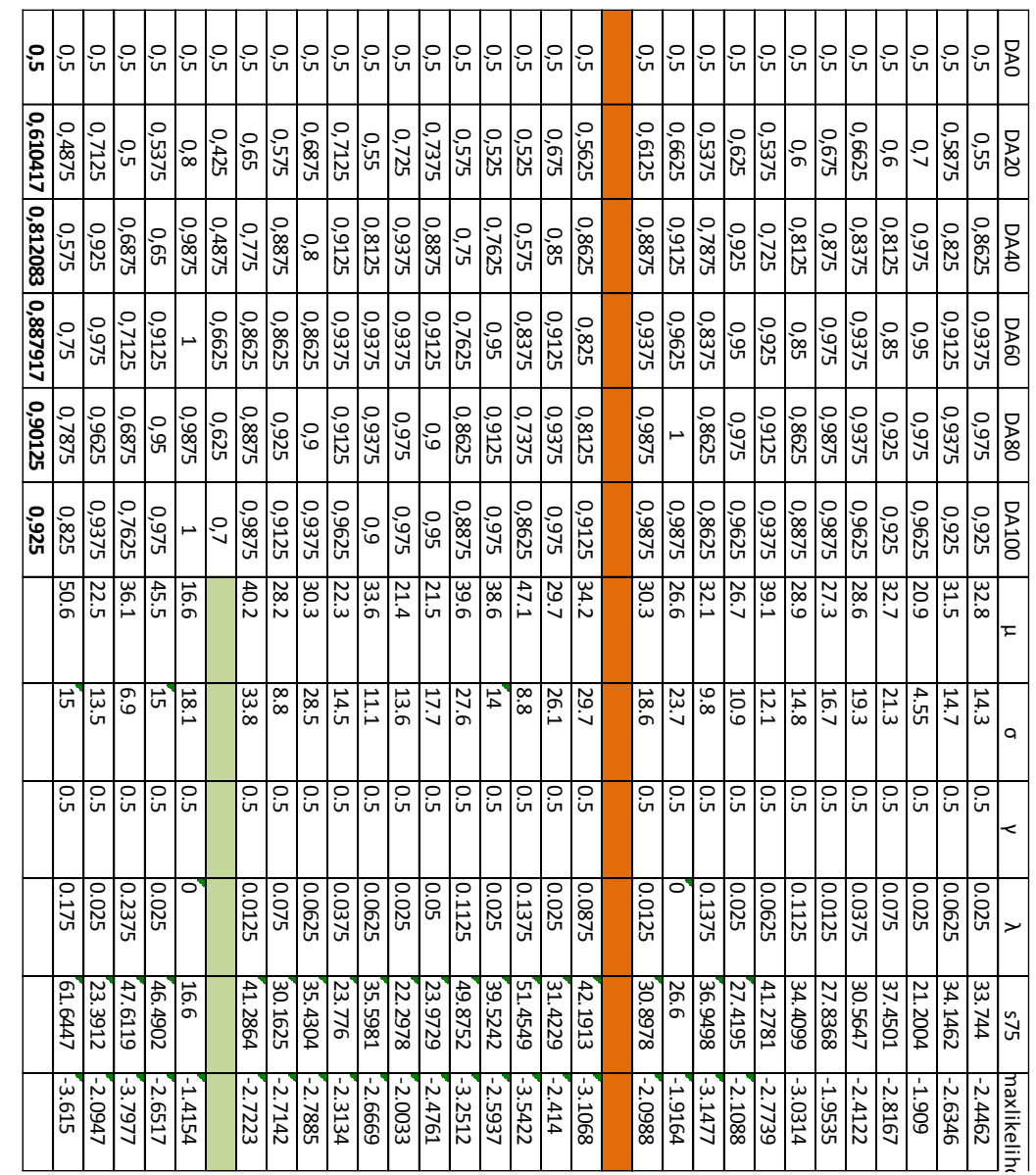


Tabela com dados de homens e mulheres e os estímulos de faces tristes

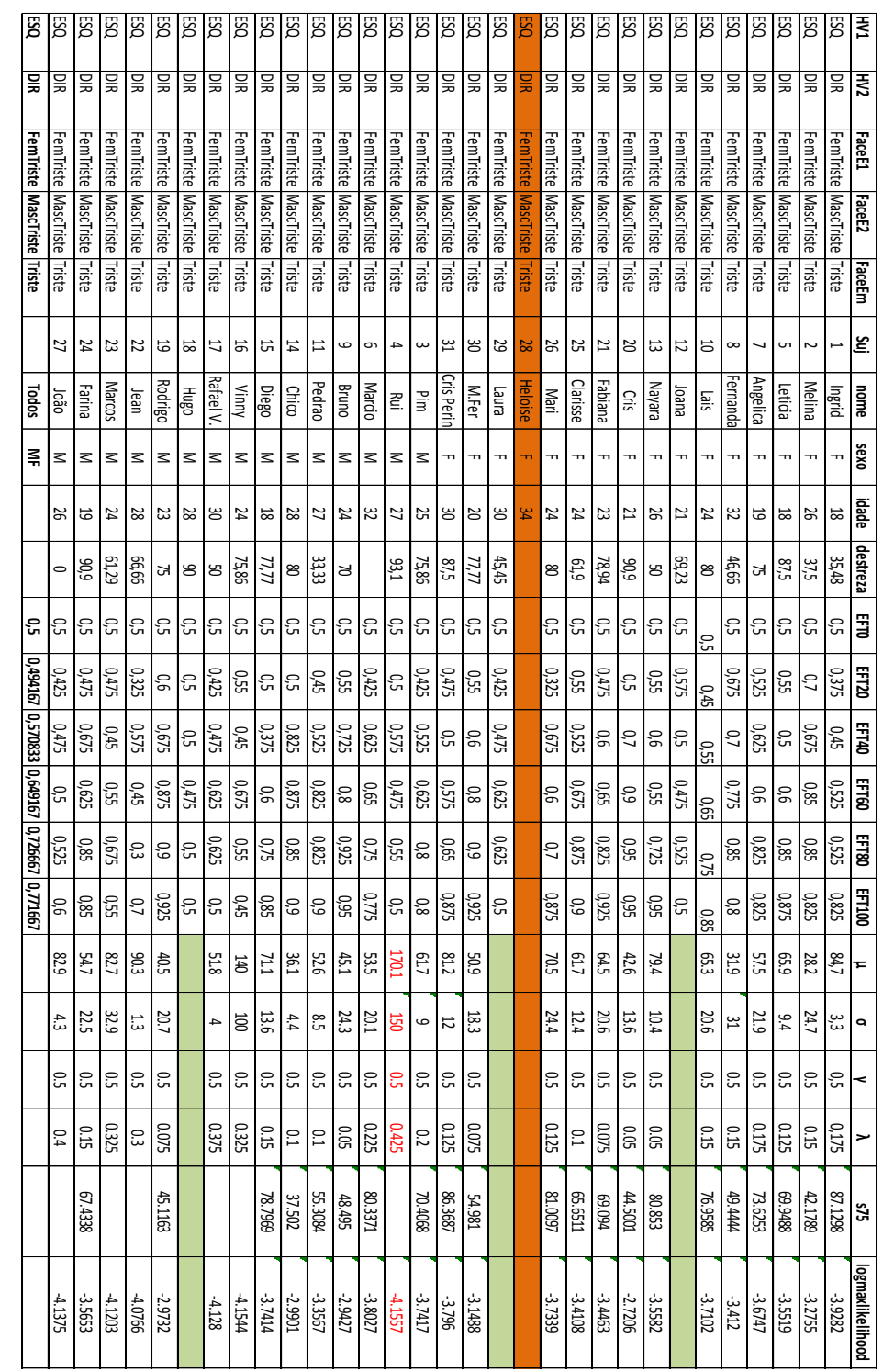




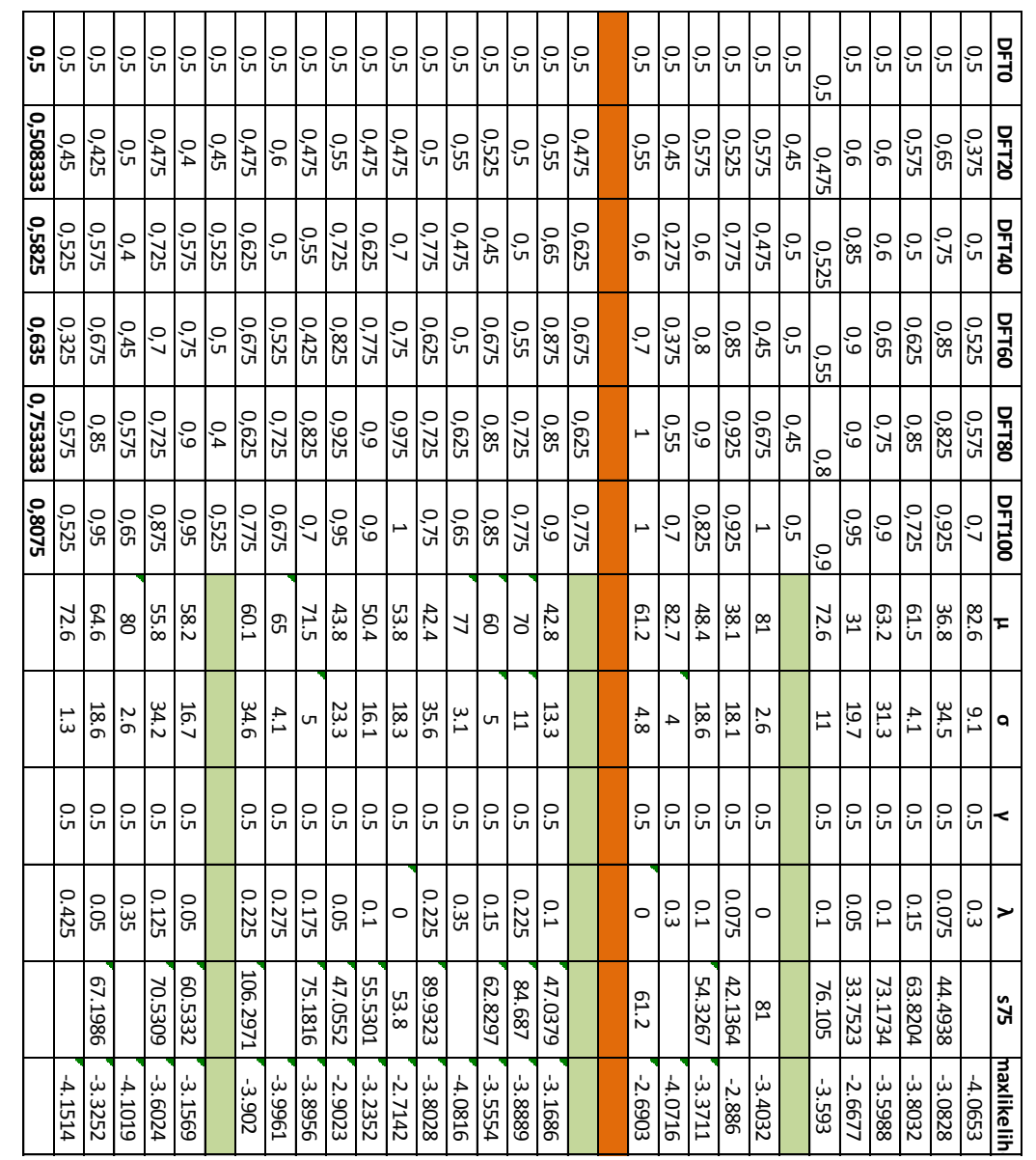

\begin{tabular}{|c|c|c|c|c|c|c|c|c|c|c|c|c|c|c|c|c|c|c|c|c|c|c|c|c|c|}
\hline 0 & & & & & & 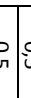 & pir & & \begin{tabular}{c|c}
0 \\
$i v$
\end{tabular} & $v_{v}$ & & 㽞 & & i & & & iv & 虽 & & $\left.\right|_{i \text { i }} ^{\infty}$ & in & 인 & & & 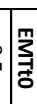 \\
\hline 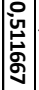 & 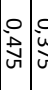 & & & & & N & & & & & & 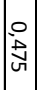 & & 语 & & & $\mid \begin{array}{l}0 \\
\text { in } \\
\text { un }\end{array}$ & 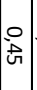 & & 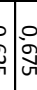 & & & & & 录 \\
\hline 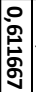 & 㽞 & & : & & $\begin{array}{c}0 \\
\text { un } \\
\text { s. }\end{array}$ & & & & & & 咅 & 品 & & i & & & 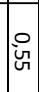 & & & 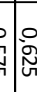 & & & & & $\frac{m}{3}$ \\
\hline $\mid$ & & & P & & of & P. & & 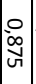 & & & $\stackrel{\circ}{\circ}$ & 0 & & $i v$ & & & $\mid \begin{array}{l}0 \\
0 \\
ن \\
ن\end{array}$ & 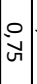 & & 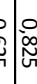 & $\begin{array}{l}0 \\
\dot{0} \\
\vdots\end{array}$ & ¿ & & & 变 \\
\hline 总 & & & 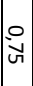 & : & 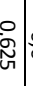 & 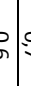 & i & 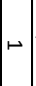 & & : & $\because$ & 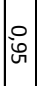 & & o & & & 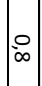 & $\mid \begin{array}{l}0 \\
0 \\
0 \\
\vdots\end{array}$ & & 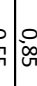 & $\begin{array}{l}\circ \\
\text { ind } \\
\text { v }\end{array}$ & & & & 昰 \\
\hline 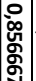 & 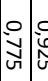 & & 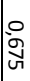 & & 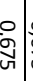 & 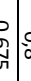 & & & & : & $\begin{array}{l}0 \\
i \\
i\end{array}$ & $\left|\begin{array}{l}0 \\
0 \\
0 \\
v \\
v\end{array}\right|$ & & 骨 & & & $\begin{array}{l}0 \\
\infty\end{array}$ & $\mid$ & & 总 & $\begin{array}{l}\circ \\
\stackrel{8}{6}\end{array}$ & s & & & 学 \\
\hline & 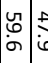 & & 8 & & जu & $\begin{array}{l}e \\
0\end{array}$ & 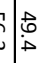 & & & & N & 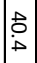 & & $\mid \underset{\sim}{N}$ & & & $\begin{array}{l}\overrightarrow{0} \\
\dot{0}\end{array}$ & 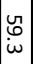 & & م. & $\omega_{\infty}$ & 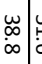 & & & $E$ \\
\hline & $|\overrightarrow{6}| \vec{\alpha}$ & 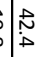 & r & & $\overrightarrow{\dot{\omega}}$ & $\vec{\omega}$ & iv & $\vec{p}$ & $\begin{array}{l}\vec{w} \\
\dot{\sim}\end{array}$ & $\vec{v}$ & & $\stackrel{\vec{\omega}}{v}$ & & 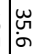 & & & $\mid \begin{array}{l}\overrightarrow{0} \\
\dot{i}\end{array}$ & $\left|\begin{array}{c}\tilde{w} \\
\infty \\
\infty\end{array}\right|$ & & 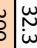 & $\stackrel{\sim}{\sim}$ & & 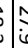 & & a \\
\hline & is & & & & in & ת & ir & ir & ir & is & is & in & & is & & & in & $\mid \begin{array}{l}0 \\
\text { ir }\end{array}$ & & o & 0 & in & & & $\mid<$ \\
\hline & i & 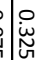 & & & 怘 & 0 & ن & $0_{0}$ & 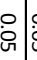 & $\dot{s}$ & 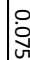 & 遂 & & 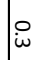 & & : & $\circ$ & $\mid$ & & : & : & & & & $>$ \\
\hline & 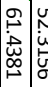 & & & & & & \begin{tabular}{l}
0 \\
\multirow{3}{*}{}
\end{tabular} & 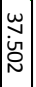 & 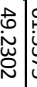 & 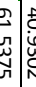 & & $\mid \begin{array}{c}\vec{N} \\
\tilde{\omega} \\
\vec{E}\end{array}$ & & & & 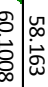 & $\begin{array}{l}8 \\
0 \\
0 \\
0 \\
0 \\
6\end{array}$ & 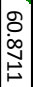 & $B$ & 泾 & & 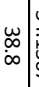 & & & $\underset{v}{v}$ \\
\hline & 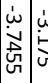 & 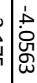 & & & & & 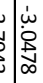 & 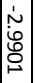 & 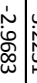 & 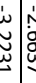 & & $\left|\begin{array}{|}\dot{\tilde{o}} \\
\dot{0} \\
\dot{0}\end{array}\right|$ & & $1+$ & & 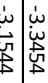 & 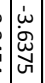 & 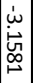 & & $\begin{array}{l}\dot{u} \\
\dot{u} \\
\dot{x}\end{array}$ & & 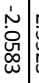 & & بُ & 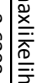 \\
\hline
\end{tabular}




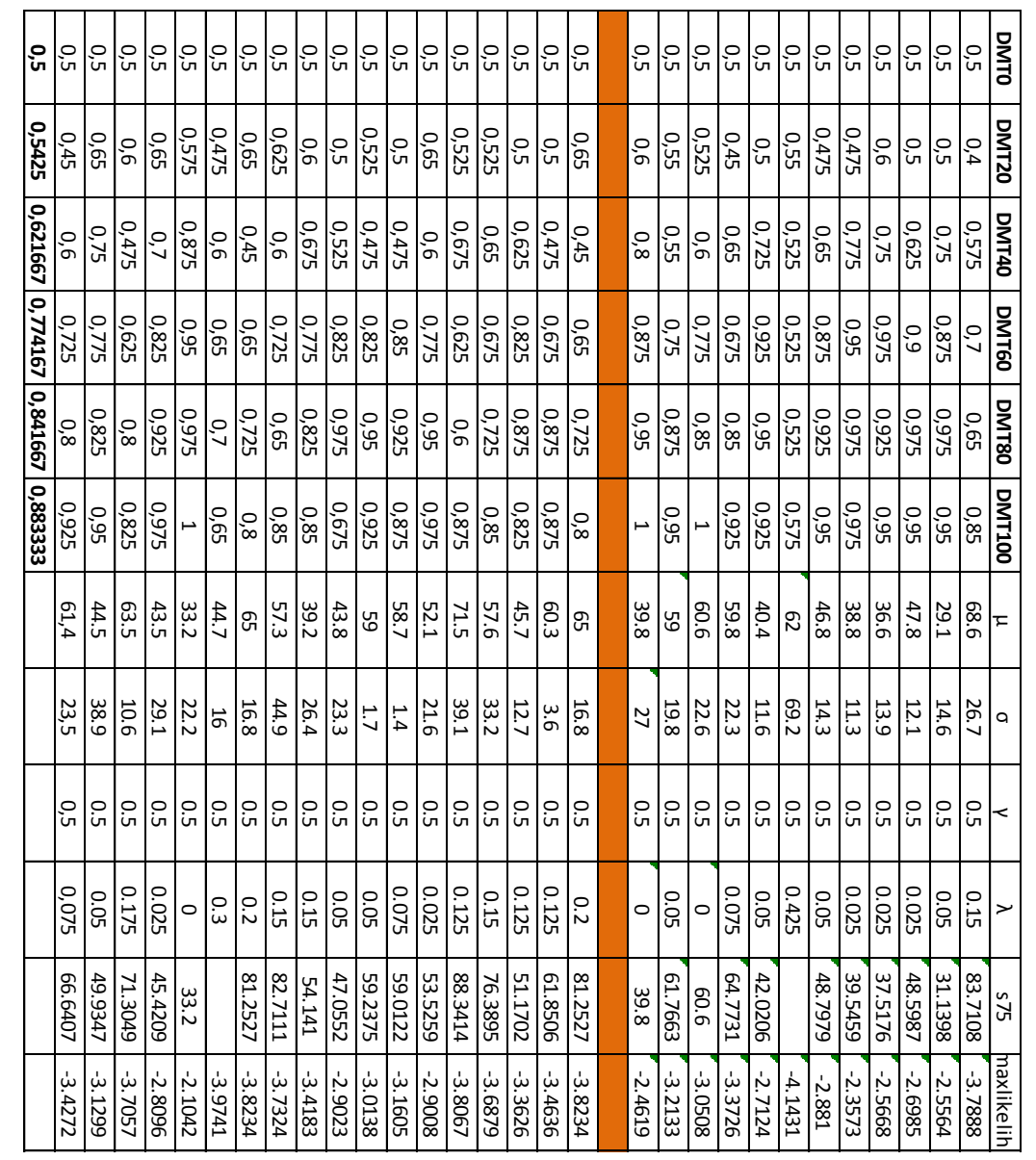

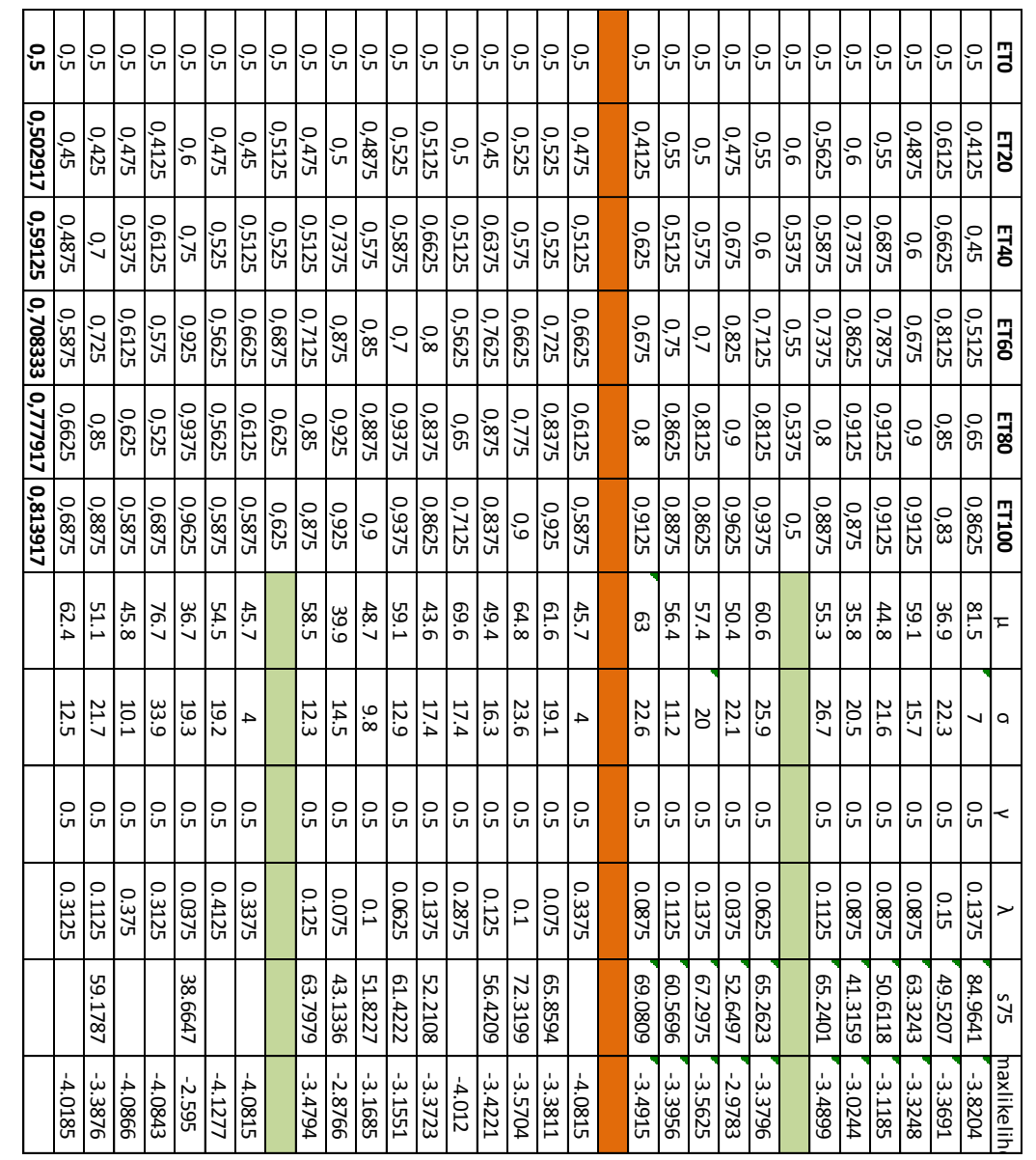




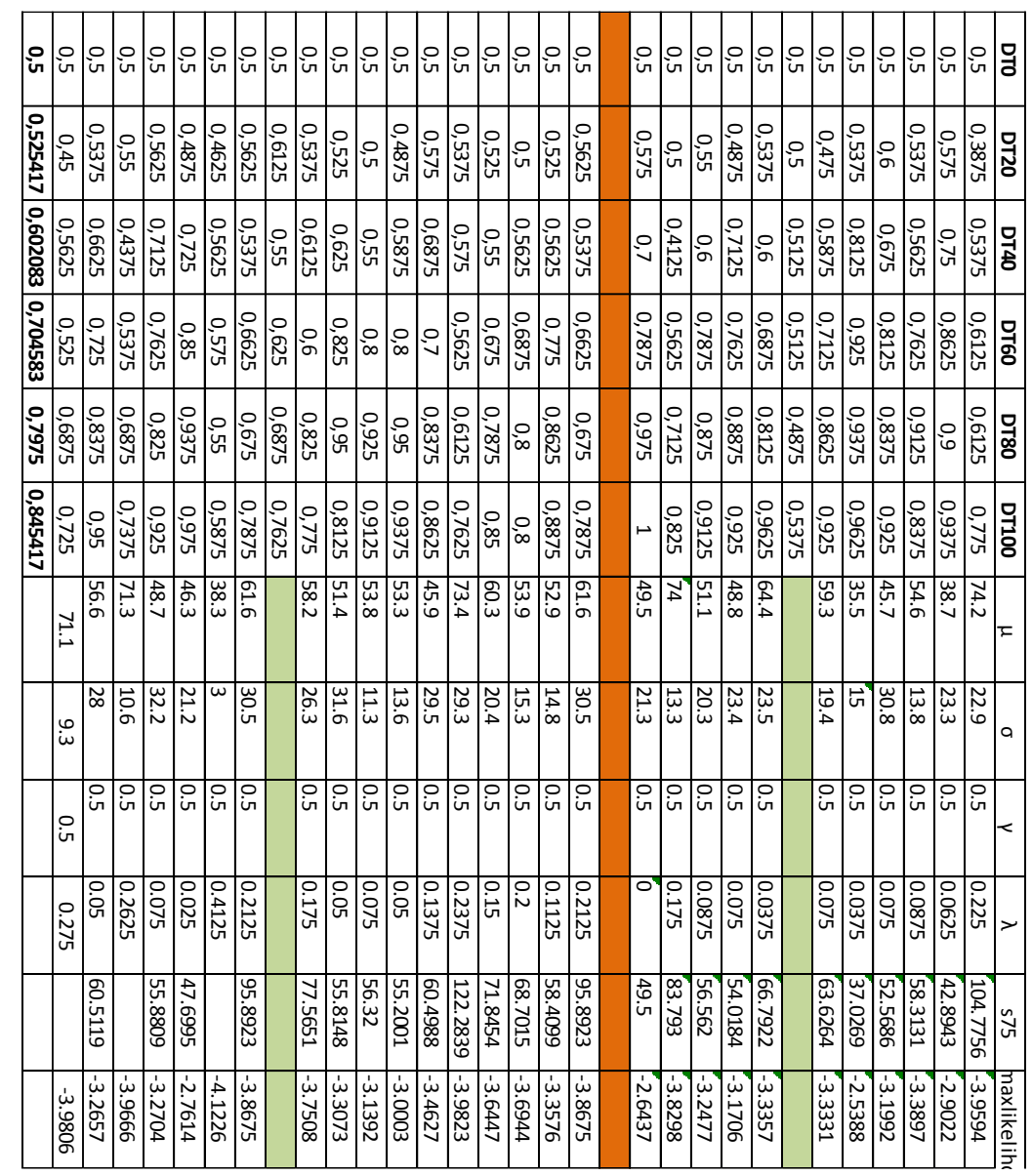


Anexo 8- Tabelas com os dados das análises estatísticas do parâmetro $\mu$

Tabela 1- Faces Alegres e Tristes

\begin{tabular}{|l|l|l|l|l|}
\hline Dados & Variável & $d f$ & $\boldsymbol{F}$-Ratio & $\boldsymbol{p}$-Value \\
\hline H e M & sexo & $(1,22)$ & 0,084 & 0,775 \\
\hline H e M & emoção & $(1,22)$ & 99,355 & $0,000^{*}$ \\
\hline H e M & emoção*sexo & $(1,22)$ & 1,570 & 0,223 \\
\hline H e M & sexo da face & $(1,22)$ & 1,454 & 0,241 \\
\hline H e M & sexo da face*sexo & $(1,22)$ & 0,138 & 0,714 \\
\hline H e M & hemicampo visual & $(1,22)$ & 0,533 & 0,473 \\
\hline H e M & hemicampo visual*sexo & $(1,22)$ & 0,028 & 0,870 \\
\hline H e M & emoção*sexo da face & $(1,22)$ & 10,634 & $0,004^{*}$ \\
\hline H e M & emoção*sexo da face*sexo & $(1,22)$ & 0,063 & 0,804 \\
\hline H e M & emoção* hemicampo visual & $(1,22)$ & 2,564 & 0,124 \\
\hline H e M & emoção* hemicampo visual*sexo & $(1,22)$ & 10,020 & $0,004^{*}$ \\
\hline H e M & sexo da face* hemicampo visual & $(1,22)$ & 1,020 & 0,323 \\
\hline H e M & sexo da face* hemicampo visual*sexo & $(1,22)$ & 4,552 & $0,044^{*}$ \\
\hline H e M & emoção*sexo da face* hemicampo visual & $(1,22)$ & 3,143 & 0,090 \\
\hline H e M & emoção*sexo da face* hemicampo visual*sexo & $(1,22)$ & 0,642 & 0,432 \\
\hline M & emoção & $(1,12)$ & 53,107 & $0,000^{*}$ \\
\hline M & sexo da face & $(1,12)$ & 1,378 & 0,263 \\
\hline M & hemicampo visual & $(1,12)$ & 0,191 & 0,670 \\
\hline M & emoção*sexo da face & $(1,12)$ & 4,324 & 0,060 \\
\hline M & emoção* hemicampo visual & $(1,12)$ & 2,027 & 0,180 \\
\hline M & sexo da face* hemicampo visual & $(1,12)$ & 14,453 & $0,003^{*}$ \\
\hline M & emoção*sexo da face* hemicampo visual & $(1,12)$ & 0,581 & 0,461 \\
\hline H & emoção & $(1,10)$ & 54,074 & $0,000^{*}$ \\
\hline H & sexo da face & $(1,10)$ & 0,316 & 0,587 \\
\hline H & hemicampo visual & $(1,10)$ & 0,334 & 0,576 \\
\hline H & emoção*sexo da face & $(1,10)$ & 6,869 & $0,026^{*}$ \\
\hline H & emoção* hemicampo visual & 7,437 & $0,021^{*}$ \\
\hline H & sexo da face* hemicampo visual & 0,332 & 0,577 \\
\hline H & emoção*sexo da face* hemicampo visual & 2,693 & 0,132 \\
\hline
\end{tabular}

$\mathrm{H}=$ homem, $\mathrm{M}=$ mulher. 
Tabela 2- Faces Alegres

\begin{tabular}{|l|l|l|l|l|}
\hline Dados & Variável & $\boldsymbol{d f}$ & $\boldsymbol{F}$-Ratio & $\boldsymbol{p}$-Value \\
\hline H e M & sexo & $(1,22)$ & 0,773 & 0,389 \\
\hline H e M & sexo da face & $(1,22)$ & 7,285 & $0,013^{*}$ \\
\hline H e M & sexo da face*sexo & $(1,22)$ & 0,665 & 0,424 \\
\hline H e M & hemicampo visual & $(1,22)$ & 3,022 & 0,096 \\
\hline H e M & hemicampo visual*sexo & $(1,22)$ & 5,182 & $0,033^{*}$ \\
\hline H e M & sexo da face* hemicampo visual & $(1,22)$ & 5,869 & $0,024^{*}$ \\
\hline H e M & sexo da face* hemicampo visual*sexo & $(1,22)$ & 0,237 & 0,631 \\
\hline M & sexo da face & $(1,12)$ & 3,230 & 0,097 \\
\hline M & hemicampo visual & $(1,12)$ & 0,162 & 0,694 \\
\hline M & sexo da face* hemicampo visual & $(1,12)$ & 4,321 & 0,60 \\
\hline H & sexo da face & $(1,10)$ & 3,850 & 0,078 \\
\hline H & hemicampo visual & $(1,10)$ & 7,222 & $0,023^{*}$ \\
\hline H & sexo da face* hemicampo visual & $(1,10)$ & 1,884 & 0,200 \\
\hline
\end{tabular}

$\mathrm{H}=$ homem, $\mathrm{M}=$ mulher .

Tabela 3 - Faces Tristes

\begin{tabular}{|l|l|l|l|l|}
\hline Dados & Variável & $\boldsymbol{d f}$ & $\boldsymbol{F}$-Ratio & $\boldsymbol{p}$-Value \\
\hline H e M & sexo & $(1,22)$ & 0,200 & 0,659 \\
\hline H e M & sexo da face & $(1,22)$ & 5,840 & $0,024^{*}$ \\
\hline H e M & sexo da face*sexo & $(1,22)$ & 0,004 & 0,949 \\
\hline H e M & hemicampo visual & $(1,22)$ & 0,109 & 0,744 \\
\hline H e M & hemicampo visual*sexo & $(1,22)$ & 2,509 & 0,127 \\
\hline H e M & sexo da face* hemicampo visual & $(1,22)$ & 0,777 & 0,388 \\
\hline H e M & sexo da face* hemicampo visual*sexo & $(1,22)$ & 2,465 & 0,131 \\
\hline M & sexo da face & $(1,12)$ & 2,939 & 0,112 \\
\hline M & hemicampo visual & $(1,12)$ & 1,188 & 0,297 \\
\hline M & sexo da face* hemicampo visual & $(1,12)$ & 0,449 & 0,516 \\
\hline H & sexo da face & $(1,10)$ & 3,080 & 0,110 \\
\hline H & hemicampo visual & $(1,10)$ & 1,268 & 0,286 \\
\hline H & sexo da face* hemicampo visual & $(1,10)$ & 1,840 & 0,205 \\
\hline
\end{tabular}

$\mathrm{H}=$ homem, $\mathrm{M}=$ mulher. 
Anexo 9 - Tabelas com os dados das análises estatísticas do parâmetro $\sigma$

Tabela 4 - Faces Alegres e Tristes

\begin{tabular}{|c|c|c|c|c|}
\hline Dados & Variável & $d f$ & F-Ratio & p-Value \\
\hline $\mathrm{H}$ e M & sexo & $(1,22)$ & 0,490 & 0,491 \\
\hline $\mathrm{H}$ e $\mathrm{M}$ & emoção & $(1,22)$ & 4,933 & $0,037^{*}$ \\
\hline $\mathrm{H}$ e $\mathrm{M}$ & emoção*sexo & $(1,22)$ & 0,002 & 0,962 \\
\hline $\mathrm{H}$ e $\mathrm{M}$ & sexo da face & $(1,22)$ & 0,548 & 0,467 \\
\hline $\mathrm{H} \mathrm{e} \mathrm{M}$ & sexo da face*sexo & $(1,22)$ & 0,001 & 0,976 \\
\hline $\mathrm{H}$ e M & hemicampo visual & $(1,22)$ & 0,042 & 0,840 \\
\hline $\mathrm{H} \mathrm{e} \mathrm{M}$ & hemicampo visual*sexo & $(1,22)$ & 6,857 & $0,016^{*}$ \\
\hline $\mathrm{H}$ e $\mathrm{M}$ & emoção*sexo da face & $(1,22)$ & 0,356 & 0,557 \\
\hline $\mathrm{H}$ e $\mathrm{M}$ & emoção*sexo da face*sexo & $(1,22)$ & 0,574 & 0,457 \\
\hline $\mathrm{H}$ e $\mathrm{M}$ & emoção* hemicampo visual & $(1,22)$ & 7,723 & $0,011^{*}$ \\
\hline $\mathrm{H}$ e $\mathrm{M}$ & emoção* hemicampo visual*sexo & $(1,22)$ & 2,096 & 0,162 \\
\hline $\mathrm{H}$ e $\mathrm{M}$ & sexo da face* hemicampo visual & $(1,22)$ & 3,124 & 0,091 \\
\hline $\mathrm{H}$ e $\mathrm{M}$ & sexo da face* hemicampo visual*sexo & $(1,22)$ & 1,421 & 0,246 \\
\hline $\mathrm{H}$ e $\mathrm{M}$ & emoção*sexo da face* hemicampo visual & $(1,22)$ & 0,045 & 0,834 \\
\hline $\mathrm{H}$ e $\mathrm{M}$ & emoção*sexo da face* hemicampo visual*sexo & $(1,22)$ & 1,557 & 0,225 \\
\hline M & emoção & $(1,12)$ & 3,761 & 0,076 \\
\hline M & sexo da face & $(1,12)$ & 1,1002 & 0,337 \\
\hline $\mathrm{M}$ & hemicampo visual & $(1,12)$ & 2,744 & 0,124 \\
\hline M & emoção*sexo da face & $(1,12)$ & 0,011 & 0,920 \\
\hline $\mathrm{M}$ & emoção* hemicampo visual & $(1,12)$ & 1,435 & 0,254 \\
\hline $\mathrm{M}$ & sexo da face* hemicampo visual & $(1,12)$ & 0,170 & 0,687 \\
\hline $\mathrm{M}$ & emoção*sexo da face* hemicampo visual & $(1,12)$ & 0,494 & 0,496 \\
\hline $\mathrm{H}$ & emoção & $(1,10)$ & 1,671 & 0,225 \\
\hline $\mathrm{H}$ & sexo da face & $(1,10)$ & 0,146 & 0,710 \\
\hline $\mathrm{H}$ & hemicampo visual & $(1,10)$ & 4,544 & 0,059 \\
\hline $\mathrm{H}$ & emoção*sexo da face & $(1,10)$ & 1,432 & 0,259 \\
\hline $\mathrm{H}$ & emoção* hemicampo visual & $(1,10)$ & 5,925 & $0,035^{*}$ \\
\hline $\mathrm{H}$ & sexo da face* hemicampo visual & $(1,10)$ & 4,371 & 0,063 \\
\hline $\mathrm{H}$ & emoção*sexo da face* hemicampo visual & $(1,10)$ & 1,265 & 0,287 \\
\hline
\end{tabular}

$\mathrm{H}=$ homem, $\mathrm{M}=$ mulher. 
Tabela 5- Faces Alegres

\begin{tabular}{|l|l|l|l|l|}
\hline Dados & Variável & $d f$ & $\boldsymbol{F}$-Ratio & p-Value \\
\hline H e M & sexo & $(1,22)$ & 0,214 & 0,648 \\
\hline H e M & sexo da face & $(1,22)$ & 0,00 & 0,999 \\
\hline H e M & sexo da face*sexo & $(1,22)$ & 0,380 & 0,544 \\
\hline H e M & hemicampo visual & $(1,22)$ & 3,634 & 0,070 \\
\hline H e M & hemicampo visual*sexo & $(1,22)$ & 0,536 & 0,472 \\
\hline H e M & sexo da face* hemicampo visual & $(1,22)$ & 1,896 & 0,182 \\
\hline H e M & sexo da face* hemicampo visual*sexo & $(1,22)$ & 2,711 & 0,114 \\
\hline M & sexo da face & $(1,12)$ & 0,162 & 0,694 \\
\hline M & hemicampo visual & $(1,12)$ & 3,653 & 0,080 \\
\hline M & sexo da face* hemicampo visual & $(1,12)$ & 0,028 & 0,869 \\
\hline H & sexo da face & $(1,10)$ & 0,266 & 0,617 \\
\hline H & hemicampo visual & $(1,10)$ & 0,668 & 0,433 \\
\hline H & sexo da face* hemicampo visual & $(1,10)$ & 7,959 & $0,018^{*}$ \\
\hline
\end{tabular}

$\mathrm{H}=$ homem, $\mathrm{M}=$ mulher .

Tabela 6 - Faces Tristes

\begin{tabular}{|l|l|l|l|l|}
\hline Dados & Variável & $d f$ & $\boldsymbol{F}$-Ratio & $\boldsymbol{p}$-Value \\
\hline H e M & sexo & $(1,22)$ & 0,303 & 0,587 \\
\hline H e M & sexo da face & $(1,22)$ & 0,755 & 0,394 \\
\hline H e M & sexo da face*sexo & $(1,22)$ & 0,323 & 0,576 \\
\hline H e M & hemicampo visual & $(1,22)$ & 4,653 & $0,042^{*}$ \\
\hline H e M & hemicampo visual*sexo & $(1,22)$ & 7,982 & $0,010^{*}$ \\
\hline H e M & sexo da face* hemicampo visual & $(1,22)$ & 1,466 & 0,239 \\
\hline H e M & sexo da face* hemicampo visual*sexo & $(1,22)$ & 0,001 & 0,978 \\
\hline M & sexo da face & $(1,12)$ & 0,076 & 0,787 \\
\hline M & hemicampo visual & $(1,12)$ & 0,319 & 0,582 \\
\hline M & sexo da face* hemicampo visual & $(1,12)$ & 0,966 & 0,345 \\
\hline H & sexo da face & $(1,10)$ & 0,668 & 0,433 \\
\hline H & hemicampo visual & $(1,10)$ & 8,918 & $0,014 *$ \\
\hline H & sexo da face* hemicampo visual & $(1,10)$ & 0,566 & 0,469 \\
\hline
\end{tabular}

$\mathrm{H}=$ homem, $\mathrm{M}=$ mulher . 
Anexo 10- Tabelas com os dados das análises estatísticas do parâmetro $\lambda$

Tabela 7 - Faces Alegres e Tristes

\begin{tabular}{|l|l|l|l|l|}
\hline Dados & Variável & $d f$ & $\boldsymbol{F}$-Ratio & p-Value \\
\hline H e M & sexo & $(1,22)$ & 0,942 & 0,342 \\
\hline H e M & emoção & $(1,22)$ & 29,074 & $0,000^{*}$ \\
\hline H e M & emoção*sexo & $(1,22)$ & 1,737 & 0,201 \\
\hline H e M & sexo da face & $(1,22)$ & 12,446 & $0,002^{*}$ \\
\hline H e M & sexo da face*sexo & $(1,22)$ & 1,843 & 0,188 \\
\hline H e M & hemicampo visual & $(1,22)$ & 2,856 & 0,105 \\
\hline H e M & hemicampo visual*sexo & $(1,22)$ & 0,407 & 0,530 \\
\hline H e M & emoção*sexo da face & $(1,22)$ & 29,067 & $0,000^{*}$ \\
\hline H e M & emoção*sexo da face*sexo & $(1,22)$ & 3,050 & 0,095 \\
\hline H e M & emoção* hemicampo visual & $(1,22)$ & 2,578 & 0,123 \\
\hline H e M & emoção* hemicampo visual*sexo & $(1,22)$ & 0,013 & 0,909 \\
\hline H e M & sexo da face* hemicampo visual & $(1,22)$ & 0,916 & 0,349 \\
\hline H e M & sexo da face* hemicampo visual*sexo & $(1,22)$ & 1,842 & 0,189 \\
\hline H e M & emoção*sexo da face* hemicampo visual & $(1,22)$ & 0,246 & 0,625 \\
\hline H e M & emoção*sexo da face* hemicampo visual*sexo & $(1,22)$ & 0,946 & 0,341 \\
\hline M & emoção & $(1,12)$ & 10,198 & $0,008^{*}$ \\
\hline M & sexo da face & $(1,12)$ & 4,775 & $0,049^{*}$ \\
\hline M & hemicampo visual & $(1,12)$ & 0,780 & 0,395 \\
\hline M & emoção*sexo da face & $(1,12)$ & 8,651 & $0,012^{*}$ \\
\hline M & emoção* hemicampo visual & $(1,12)$ & 1,115 & 0,312 \\
\hline M & sexo da face* hemicampo visual & $(1,12)$ & 0,085 & 0,775 \\
\hline M & emoção*sexo da face* hemicampo visual & $(1,12)$ & 0,079 & 0,783 \\
\hline H & emoção & $(1,10)$ & 18,314 & $0,002^{*}$ \\
\hline H & sexo da face & $(1,10)$ & 7,087 & $0,024^{*}$ \\
\hline H & hemicampo visual & $(1,10)$ & 1,968 & 0,191 \\
\hline H & emoção*sexo da face & $(1,10)$ & 19,681 & $0,001^{*}$ \\
\hline H & emoção* hemicampo visual & $2,10)$ & 2,546 & 0,142 \\
\hline H & sexo da face* hemicampo visual & 3,051 & 0,111 \\
\hline H & emoção*sexo da face* hemicampo visual & $(1,10)$ \\
\hline
\end{tabular}

$\mathrm{H}=$ homem, $\mathrm{M}=$ mulher. 
Tabela 8- Faces Alegres

\begin{tabular}{|l|l|l|l|l|}
\hline Dados & Variável & $\boldsymbol{d f}$ & $\boldsymbol{F}$-Ratio & $\boldsymbol{p}$-Value \\
\hline H e M & sexo & $(1,22)$ & 0,006 & 0,942 \\
\hline H e M & sexo da face & $(1,22)$ & 1,280 & 0,270 \\
\hline H e M & sexo da face*sexo & $(1,22)$ & 0,001 & 0,993 \\
\hline H e M & hemicampo visual & $(1,22)$ & 0,466 & 0,502 \\
\hline H e M & hemicampo visual*sexo & $(1,22)$ & 0,680 & 0,419 \\
\hline H e M & sexo da face* hemicampo visual & $(1,22)$ & 0,117 & 0,736 \\
\hline H e M & sexo da face* hemicampo visual*sexo & $(1,22)$ & 0,037 & 0,850 \\
\hline M & sexo da face & $(1,12)$ & 0,769 & 0,398 \\
\hline M & hemicampo visual & $(1,12)$ & 0,017 & 0,897 \\
\hline M & sexo da face* hemicampo visual & $(1,12)$ & 0,008 & 0,928 \\
\hline H & sexo da face & $(1,10)$ & 0,532 & 0,483 \\
\hline H & hemicampo visual & $(1,10)$ & 0,725 & 0,415 \\
\hline H & sexo da face* hemicampo visual & $(1,10)$ & 0,290 & 0,602 \\
\hline
\end{tabular}

$\mathrm{H}=$ homem, $\mathrm{M}=$ mulher.

Tabela 9 - Faces Tristes

\begin{tabular}{|l|l|l|l|l|}
\hline Dados & Variável & $\boldsymbol{d f}$ & $\boldsymbol{F}$-Ratio & $\boldsymbol{p}$-Value \\
\hline H e M & sexo & $(1,22)$ & 1,577 & 0,222 \\
\hline H e M & sexo da face & $(1,22)$ & 20,664 & $0,001^{*}$ \\
\hline H e M & sexo da face*sexo & $(1,22)$ & 2,558 & 0,124 \\
\hline H e M & hemicampo visual & $(1,22)$ & 3,565 & 0,072 \\
\hline H e M & hemicampo visual*sexo & $(1,22)$ & 0,143 & 0,709 \\
\hline H e M & sexo da face* hemicampo visual & $(1,22)$ & 0,659 & 0,426 \\
\hline H e M & sexo da face* hemicampo visual*sexo & $(1,22)$ & 1,737 & 0,201 \\
\hline
\end{tabular}

$\mathrm{H}=$ homem, $\mathrm{M}=$ mulher. 
